Review

\title{
The New Genetics and Natural versus Artificial Genetic Modification
}

\author{
Mae-Wan Ho \\ Institute of Science in Society, 29 Tytherton Road, London N19 4PZ, UK; \\ E-Mail: m.w.ho@i-sis.org.uk; Tel./Fax: +44-0-20-7272-5636
}

Received: 2 August 2013; in revised form: 9 October 2013 / Accepted: 10 October 2013 /

Published: 4 November 2013

\begin{abstract}
The original rationale and impetus for artificial genetic modification was the "central dogma" of molecular biology that assumed DNA carries all the instructions for making an organism, which are transmitted via RNA to protein to biological function in linear causal chains. This is contrary to the reality of the "fluid genome" that has emerged since the mid-1970s. In order to survive, the organism needs to engage in natural genetic modification in real time, an exquisitely precise molecular dance of life with RNA and DNA responding to and participating in "downstream" biological functions. Artificial genetic modification, in contrast, is crude, imprecise, and interferes with the natural process. It drives natural systems towards maximum biosemiotic entropy as the perturbations are propagated and amplified through the complex cascades of interactions between subsystems that are essential for health and longevity.
\end{abstract}

Keywords: central dogma; fluid genome; circular causation; biosemiotics

\section{Introduction}

It has been almost 20 years since the first genetically modified organism (GMO) entered the market [1]. A GMO is simply any organism (plant, animal fungi, bacteria or virus - not strictly an organism) with synthetic genetic material inserted into its genome ("genome" in this context includes extrachromosomal plasmids and mitochondrial and chloroplast DNA); it is made in the laboratory with sterile techniques, which also means without the need for sexual reproduction between donor and recipient species of the genetic material. The basis for such genetic manipulation was the "central dogma" of molecular biology due to Francis Crick [2,3], who shared the Nobel Prize with James 
Watson for the DNA double helix structure [4]. As Oller stated at the beginning of this special issue [5], Crick's oversimplified dogma proposed that biologically meaningful information could only flow from DNA through RNA to proteins, and so forth to cells, organs, organisms and species; and nothing could be added to the DNA program from the outside by any means. Gryder et al [6] in this series have developed their argument about cancers on the same doctrine, although both Oller [5] and Gryder et al [6] acknowledge that the central dogma is an oversimplification. Yet, that dogma remains the basis for genetic engineering. It is supposed that individual "genetic messages" in DNA are faithfully copied or transcribed into RNA, which are then translated into proteins via a genetic code; each protein supposedly determining a particular trait, such as herbicide tolerance, or insect resistance; one-gene-one-character. Hence inserting a new genetic message into an organism will give it the desired character to serve our every need. If it were really as simple as that, genetic modification would work perfectly every time. Unfortunately things are vastly more complicated.

Samsel and Seneff have exposed the-one-gene-one-character fallacy by documenting the wide-spread impact of the herbicide-tolerant trait in GM crops on the health of crops, animals and consumers [7]. In this article, I review further empirical evidence on how artificial genetic modification disrupts the natural process, ultimately resulting in the maximization of biosemiotic entropy [5].

\section{The Fluid Genome and Natural Genetic Engineering}

In Genetic Engineering Dream or Nightmare [8], I described the new genetics of the "fluid genome" - a term coined by molecular geneticists that appeared on the back cover of a popular book published in the early 1980s [9] and warned that the greatest danger of genetic modification is its being misguided by the ideology of genetic determinism (the "central dogma" of the old genetics). Genetic determinism made genetic modification seem compelling, but was totally contrary to reality, as documented in [9] and numerous reviews and books since (see for example [10-17]; though none of the publications except [15] has dealt explicitly with the perspective presented here).

Instead of the linear, one-way information flow envisaged in the central dogma from DNA to RNA to protein and "downstream" biological function, there is intricate cross-talk between the organism and its environment at all levels, with feed-forward and feed-back cycles in the epigenetic and metabolic networks of molecular interactions that mark and change genes as the organism goes about its business of living, with effects reverberating and amplified down the generations [14,15]. This cross-talk not only involves different parts of the organisms, but as the Dieterts [18] and Kosov [19] have pointed out in this special issue [20], it extends to the microbiota within the organism (in the digestive tract, for example), as well as species in the larger external environment [19], and the ecosystem as a whole,

The organism is doing its own natural genetic modification (c.f. James Shapiro's "natural genetic engineering" [12]) with great finesse, a molecular dance of life that's necessary for survival. Unfortunately, genetic engineers do not know the steps or the rhythm and music of the dance; they are only now tracing its footprints in the genome: how DNA and histone proteins are marked, or DNA and RNA are changed for example. It is clearly impossible to modify one gene or one function at a time without affecting other functions, ultimately the entire organism and its ecosystem. It is also this molecular dance of life that makes organisms and ecosystems vulnerable to the unintended effects of genetic modification as will be made clear in this paper. Furthermore, the insults and injuries to 
organisms and ecosystems exposed to the GMOs can be passed on to future generations to influence the course of evolution.

In the new genetics of the fluid genome, causation is circular; it goes from DNA to RNA to protein and back to DNA; not via reverse translation, but by means of proteins and RNA working in numerous ways to alter the "genetic messages" in DNA, including its base sequence.

In retrospect, this makes perfect sense, because the "instructions" written in the DNA can never fully anticipate what the organism will experience throughout its life. In the scheme of biosemiotics as explained by Oller [5], the DNA is the symbolic level S; if so, it has to represent accurately the objects of experience $\mathrm{O}$ (the sensory and physical inputs from the environment to the organism), with RNA as the index level $\pi$ connecting S and O. If Crick's idea were correct, the mapping of DNA to RNA to protein would represent a valid narrative-like representation. However, the biosemiotic systems are more complex. Without the objects of experience, there can be no sensible symbolic level. Genomic DNA is not only a text whose meaning changes with experience, it is subject to revision, a changing narrative that prepares us for life at the next stage, and also enables us to pass on our experiences to the next generation, for better or for worse. RNA is far from a simple transcript of the genetic message; but can change and corrupt the message (through RNA editing [21]), destroy it (by RNA interference [22]), or rewrite the DNA text (by reverse transcription and gene conversion [23,24]).

In reality, the organism shapes its own development and evolutionary future; that is why it is so important to take responsible action (see Figure 1) [25]. Indeed, new findings on the fluidity and responsiveness of the genome have made the hazards of genetically modified DNA and RNA even greater than anyone has envisaged, as I shall elaborate in this review.

Figure 1. The new genetics of the fluid genome versus the old genetics of the central dogma [25].

THE NEW Genetics OF THE FLUID GENOME

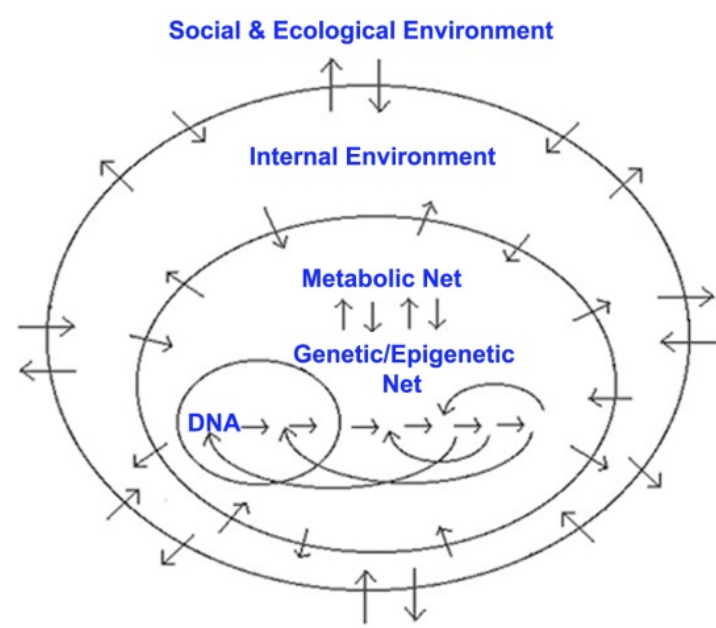

THE CENTRAL DOGMA

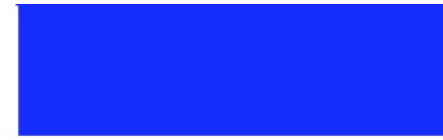

* Heredity is distributed over the entire web of organismenvironment interrelationships from the social \& ecological to the genetic \& epigenetic

* There is no separation between development and evolution

* The organism participates in shaping its own development and evolutionary future

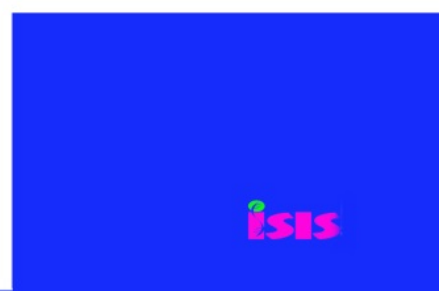




\section{Genetic Modification Inherently Hazardous}

Reliable evidence obtained by scientists independent of the biotech industry going back to the 1990s and evidence obtained by farmers in the field both show that GM feed invariably causes harm, regardless of the animal species or the food crops genetically modified or the genes and constructs inserted into the genome. A list is presented in Box 1, partly drawn from a review published in 2007 [26] and updated with studies done and cases uncovered since, including an independent meta-analysis of data in 19 feeding trials from the biotech industry.

Box 1. Accumulating evidence on the health hazards of GM food and feed.

1. A paper just published in 2013 reports significantly higher rates of severe stomach inflammation in pigs fed a mixed GM corn and soybean diet for 22.7 weeks compared with pigs fed an equivalent non-GM control diet: $32 \%$ compared to $12 \%$. Female pigs on the GM diet also had uterus heavier by $25 \%$ on average [27].

2. A 2-year lab feeding trial reported in 2012 found rats of both sexes exposed to Roundup and/or Roundup-tolerant maize not sprayed with herbicide were 2 to 3 times as likely to die as controls and to develop large tumours, of mammary glands in females and of kidney and skin in males [28] (see also [29,30]). In other words, the GMO without the herbicide was also harmful in every respect. Pituitary disease was up more than 2 fold in females and liver and kidney diseases up 1.5 to 2 fold in males on GM maize alone that was not sprayed with herbicide. These effects appeared after the 90 days period legally required for safety tests on GMOs, thereby exposing the inadequacy of the regulatory regime.

3. A Danish farmer found excessive illnesses and deaths in his pigs fed GM soy meal including chronic diarrhoea, birth defects, reproductive problems, bloating, stomach ulcers, weak and smaller piglets, and reduced litter size. These were entirely reversed when he put them on a GM-free diet [31].

4. A meta-analysis pooling all available data on 19 feeding trials carried out for 90 days on GM soybean and maize, both glyphosate tolerant and Bt crops representing $83 \%$ of commercialized GMOs - a period inadequate for detecting the most serious health impacts - nevertheless found significant disruption of liver and kidney functions [32,33].

5. Professor emeritus Don Huber at Purdue University warned of "pathogen new to science" associated with glyphosate tolerant GM crops and livestock fed on them, causing unprecedented deaths and infertility [34,35].

6. Between 2005 and 2006, senior scientist Irina Ermakova at the Russian Academy of Sciences reported that female rats fed glyphosate-tolerant GM soybeans produced excessive numbers of severely stunted pups and more than half of the litter dying within three weeks, while the surviving pups were completely sterile [36,37]. 
Box 1. Cont.

7. Between 2004 and 2005, hundreds of farm workers and cotton handlers in Madhya Pradesh, India, reported allergy symptoms from exposure to Bt cotton containing Cry1Ac or both Cry1Ac and Cry1 Ab proteins [38].

8. Between 2005 and 2006, thousands of sheep died after grazing on Bt cotton crop residues in four villages in the Warangal district of Andhra Pradesh in India [39].

9. In 2005, scientists at the Commonwealth Scientific and Industrial Research Organization in Canberra Australia tested a transgenic pea containing a normally harmless protein in bean (alpha-amylase inhibitor 1), and found it caused inflammation in the lungs of mice and provoked sensitivities to other proteins in the diet [40,41].

10. From 2002 to 2005, scientists at the Universities of Urbino, Perugia and Pavia in Italy published reports indicating that GM-soya fed to young mice affected cells in the pancreas, liver and testes [42-46].

11. In 2003, villagers in the south of the Philippines suffered mysterious illnesses when a Monsanto Bt maize hybrid containing Cry $1 \mathrm{Ab}$ protein came into flower; antibodies to the $\mathrm{Cry} 1 \mathrm{Ab}$ protein were found in the villagers, there have been at least five unexplained deaths and some remain ill to this day [47].

12. In 2004, Monsanto's research dossier, kept confidential for commercial reasons, showed that rats fed MON863 GM maize containing Cry3Bb protein developed serious kidney and blood abnormalities [48].

13. Between 2001 and 2002, a dozen cows died in Hesse Germany after eating Syngenta GM maize Bt176 containing Cry1Ab/Cry1Ac plus glufosinate-tolerance; and more in the herd had to be slaughtered from illnesses [49]. In 2012, biotech giant Syngenta was criminally charged with denying knowledge it had since 1996, that its GM maize kills livestock, during a civil court case brought by the farmer that ended in 2007 [50].

14. In 1998, senior scientist Arpad Pusztai and colleagues formerly of the Rowett Institute in Scotland reported damage in every organ system of young rats fed GM potatoes containing snowdrop lectin, including a stomach lining twice as thick as controls [51].

15. Also in 1998, scientists in Egypt found similar effects in the gut of mice fed Bt potato containing a Cry1A protein [52].

16. In 2002, Aventis company (later Bayer Cropscience) submitted data to UK regulators showing that chickens fed glufosinate-tolerant GM maize Chardon LL were twice as likely to die compared with controls [53].

It presents a consistent picture of GM-linked deaths and illnesses, with scientists confirming what farmers have been experiencing and witnessing for years. This is all the more significant, as independent scientific studies are hard to come by because of lack of support; and scientists find it very difficult to obtain the GM material from the biotech companies for their research or to publish their results [54]. The inevitable conclusion one comes to is that GM is inherently hazardous. 


\section{Sources of Hazards from GMOs}

There are many possible sources of hazards of GMOs associated with the fluid and responsive genome; I have put them into four categories in Table $1[8,55,56]$. Despite the paucity of dedicated research, there is now substantial evidence that GM food and feed is unsafe, both from lab studies by independent scientists, and from farmers' experiences in the field all over the world (Box 1). There is also evidence that GM crops yield less, poison crops and soil, and cause the emergence and re-emergence of many crop diseases reviewed elsewhere [57,58].

Table 1. Hazards of GMOs.

\begin{tabular}{l} 
1. Uncontrollable, unpredictable impacts on safety due to the genetic modification process * \\
Scrambling the host genome * \\
Widespread mutations * \\
Inactivating genes * \\
Activating genes * \\
Creating new transcripts (RNAs) including those with regulatory functions * \\
Creating new proteins * \\
Creating new metabolites or increasing metabolite to toxic levels * \\
Activating dormant viruses * \\
Creating new viruses by recombination of viral genes in GM insert with those in the host \\
genome * \\
2. Toxicity of transgene protein(s) introduced (intentionally or otherwise) \\
Transgene protein toxic * \\
Transgene protein allergenic or immunogenic * \\
Trangenic protein becoming allergenic or immunogenic due to processing * \\
Unintended protein created by sequence inserted may be toxic or immunogenic \\
3. Effects due to the GM insert and its instability * \\
Genetic rearrangement with further unpredictable effects * \\
Horizontal gene transfer and recombination* \\
Spreading antibiotic and drug resistance * \\
Creating new viruses and bacteria that cause diseases \\
Creating mutations in genomes of cells to which the GM insert integrate \\
including those associated with cancer * \\
4. Toxicity of herbicides used with herbicide tolerant GM crops * \\
\hline Documented in scientific literature, as reviewed in the main text.
\end{tabular}

Although the weight of evidence against the safety of GMOs is substantial, we are still largely in the dark as to the precise nature of the hazard(s) associated with individual GMOs. Toxicity has been found for transgene products such as the Bt proteins from different strains of the soil bacteria Bacillus thuringiensis expressed in many GM crops [58], while the multiple toxicities and carcinogenicity of glyphosate herbicides, heavily used with glyphosate tolerant GM crops, are no longer in doubt [57]. One recent review even blames glyphosate for most, if not all increases in chronic diseases in recent years [7]. There remains a range of hazards that are not so easily identified, even though evidence exists for most, if not all of them in the scientific literature (see later). These are due to the unpredictability and uncontrollable nature of the genetic modification process (Table 1, category 1), 
which can activate or inactivate genes, scramble genomes, create new proteins, new nucleic acids, new metabolites, and others due to the transgenic DNA and its instability (Table 1 category 3), of horizontal gene transfer - the direct transfer of DNA into the genomes of cells - from the GMO to all other species interacting with the GMO. To identify those hazards require genome sequencing and detailed comparisons of transcriptome, epigenome, proteome, and metabolome, techniques for which are all easily available today, and should be mandatory in the current regulatory regimes for risk assessment of GMOs, but are not.

\section{Natural and Artificial Genetic Modification Are Completely Distinct}

There are big differences between natural and artificial genetic modification. Natural genetic modification is quite precise and predictable; regardless of whether it is epigenetic marking of DNA that activate or inactivate genes [13], RNA-editing that changes the base sequence of transcripts before translation [16,21], or "directed (adaptive) mutations", the repeatable appearance of specific mutations in response to given environmental stimuli $[59,60]$. It is negotiated by the organism as a whole, and occurs at the right time and place without damaging the genome. It is appropriate to the organism as a whole in its environmental context (which does not mean it is always adaptive, however, for an adverse environment can certainly result in directed mutations for certain cells to multiply and develop into tumours or cancers that are not adaptive for the organism as a whole). How the organism manages to do that is among the greatest unsolved mysteries. Some of us have suggested that the new genetics of the fluid genome belongs in the organic paradigm of quantum biology [61], and the organism is actually the living incarnation of the elusive quantum computer [62] that has been the holy grail of quantum physicists for more than 30 years. Quantum coherent organisms intercommunicate via coherent electromagnetic signals, and there is indeed evidence that molecules do just that. Molecules that react together share common frequencies to which they resonate, thereby attracting one another [63]. That may well be how specific genes are directed to mutate during metabolic stress, the genes being just those coding for enzymes that can metabolize a new substrate presented to the starved cells [64].

In contrast, artificial genetic modification is crude, imprecise, unpredictable, and uncontrollable. The artificial constructs or transgenes - cobbled together from DNA copied from various sources or purely synthetic with no natural counterpart-are smuggled into cells using disarmed pathogenic viruses or bacteria as vectors, or else forced into the cell with gene guns or electric shocks. There is no control over where and in what forms the constructs land in the genome, and a lot of collateral damage is also inflicted on the genome, including rearrangements, sequence scrambling, deletions, mutations (see $[15,57,65])$. In addition, aggressive promoters, often from viruses are used to drive gene expression, essentially out of context. In semiotic terms [20], the artificial construct lacks meaning within the genome and the host organism (it sends out the wrong signals), and is in constant conflict with the host organism.

There is hence nothing natural about artificial genetic modification. Furthermore, artificial genetic modification is greatly enhanced horizontal gene transfer. The GM constructs are designed to cross species barriers and to jump into genomes $[8,15]$. Genes are transferred between species that would never have exchanged genes otherwise. Thus, DNA from one species can be transferred into another living on the opposite side of the globe, and DNA from species extinct for hundreds of thousands of years can nevertheless be copied and transferred into living species. In addition, GM constructs tend to be 
unstable, with weak joints from being cobbled together from diverse sources, as well as from well-known break points associated with promoters and terminators; and hence more prone to further horizontal gene transfer after it has integrated into the genome (see [15]). A study comparing the spread of herbicide tolerance in a transgene with the same trait in a mutation [66] found that the transgene was up to 30 times more likely to escape and spread to neighbouring plants; the most likely reason is by horizontal gene transfer, via insects and bacteria.

\section{Transgene Instability and the Illegality of GMOs}

Since the 1990s, some of us have raised the possibility of unintended secondary horizontal gene transfer from GMOs released into the environment with detailed reviews and reports, many of which were sent to our regulators (see for example [67-70]). At first the regulators and GM proponents denied that horizontal gene transfer could happen at all, or the probability is so tiny as to be practically zero [5]. Later, when it became clear from molecular genetic analyses that rampant horizontal gene transfer had taken place in the course of evolution and in recent times (see for example [71]), they said horizontal gene transfer is a natural process, and therefore no need to worry; and anti-GM is just anti-science (see for example [72]).

Horizontal gene transfer is indeed a natural genetic modification process, normally under the control of the organism itself and will take place when the conditions are right, and the organism is ready, without damaging the genome, and this is so in microorganisms as well as cells of higher organisms including humans (see section 11). That is why GM DNA is such a threat. On account of its increased propensity for horizontal gene transfer, GM DNA can take over the natural process to gain access to the organisms' genome regardless of whether it is appropriate to the organism or not.

The increased propensity of GM DNA for horizontal gene transfer contributes to the instability of transgenic lines. Transgenes not only get silenced (no longer expressed) in successive generations, but can also become rearranged, or lost. Transgene instability is an open secret within the permissive regulatory regime.

In 2003, independent scientists characterized the GM insert in all the commercially approved transgenic lines in Europe, and found every one of them had undergone rearrangement [73,74]. According to European Directive 2001/18/EC, that would make them illegal, as they were not the "event-specific" lines originally characterized and approved for commercial release [75]. Event-specific characterisation in risk assessment is essential because the transgenic process is uncontrollable and unpredictable. The properties of the transgenic line depend entirely on where and in what form the transgenic DNA has landed and the collateral damage done to the genome in the event. Consequently, molecular genetic data confirming that the transgenic line derived from the event is genetically stable have to be provided to the regulators. That should be data showing that the insert has remained in the same form in the same genome site with identical flanking host genome sequences for a number of generations [76], as demonstrated by analysing a random selection of plants from each generation. But this requirement is seldom if ever implemented by the regulators, which have accepted phenotypic stability as a surrogate for genetic stability.

Transgene instability makes a mockery of the risk assessment process, because any change in transgene expression, or worse, rearrangement or movement of the transgenic DNA insert(s) would 
create another transgenic plant different from the one that was characterized and risk assessed. And it matters little how thoroughly the original characterization and risk assessment may have been done. Later analyses of one of the lines, MON810, indicated further rearrangements have taken place [77]. MON810 was analysed again a few year later and confirmed to have a different insertion site as well as new mRNA transcripts representing fusion proteins between crylA transgene and host genome sequences, adding 2 or 18 amino acids to the Cry1A protein [78,79] (see [80,81] for the significance of these rearrangements).

The legislature should take note: unstable transgenic lines are illegal. Not only should they not be still growing commercially, they are also strictly ineligible for patent protection. According to a review published in 2004, the loss of transgenes during reproduction occurs at a frequency of 10 to $50 \%$ of transgenic plants, regardless of how they are produced [82]. Transgene instability appears to depend on the nature of the transgene, the host genome, and the site of integration, and not on the transformation method. There may be integration hotspots in the genome that are inevitably also disintegration hotspots, as revealed by experiments in "gene therapy" [83] in human cells, and confirmed in large scale analysis of transgenic integration in plants [84] and in the common carp [85].

In plants, transgene integration sites resulting from all transformation systems (except for homologous recombination) exhibit short sequence homologies between the integrated transgenic DNA and flanking genomic sequences of 1 to $8 \mathrm{bp}$, and between the rearranged transgene fragments [84]. Transgenes tend to be integrated into gene-rich regions, and reduced in the centromere regions of chromosomes. They also show propensity for AT-rich regions and at transitions between normal base composition to a poly-T or A-rich region. These "hotspots" for integration may be sites that tend to be exposed and break more often, and hence also hotspots for dis-integration. Another reason for transgenic instability is the genetic modification process itself, which may destabilise the genome by causing genome scrambling and chromosomal abnormalities. In terms of biosemiotics [5], the transgenic DNA lacks coherent "meaning" in the context of the genome and organismic system as a whole; and this may also be a reason for its instability, as the organismic system attempts to restore balance and coherence. Transgene instability is now widely reported in the scientific literature, and some examples are given below.

Apple cultivars were transformed using Agrobacterium vector to increase resistance to diseases like powdery mildew, apple scab and fire blight [86]. A total of 64 plants of 15 different transgenic apple lines were transferred to the greenhouse, half of them grown as own rooted trees, and half grafted in different non-transgenic scion-rootstock. When tested after an unspecified time, 22 of the plants (34\%) lost one or both genes. In the rest, four plants did not express the antibiotic marker gene, one had lost its promoter and in other three, the promoter was silenced (not functional). In a second experiment, 26 lines carrying the attacin E gene from Hyalophora cecropia, the $\beta$-glucuronidase (gus) gene and the nptII gene were propagated vegetatively in vitro without selective agents for 4 years (50 generations) and then analysed [87]. Neither expression nor integration remained stable in some lines, differences were found between plants of a single line and several plants were chimaeras of expressing and non-expressing cell clones. For example, twenty-three lines kept all three genes (at least in some of the plants). One line lost gus $A$ and two lines lost all genes. Low levels of nptII expression were found in 12 lines, increased expression in 10 lines and only two had the same level of protein expression. Stable expression of gus was found in eight lines, though some plants were mosaics of cells that expressed the gene and cells that did not, Two lines had no activity at all, even though one had the gene. 
Researchers in Brazil identified a remarkable systematic elimination of transgenes in a transgenic dry bean and a transgenic soybean at reproduction [88]. The dry bean (Phaseolus vulgaris L.) line was obtained by particle bombardment with plasmid pMD4 containing the gus gene and the rep-trap-ren genes from bean golden mosaic geminiviru, both under the control of the CaMV (cauliflower mosaic virus) $35 \mathrm{~S}$ promoter, to make it immune to the golden mosaic geminivirus. The soybean line was transformed with another plasmid pAG1 that contains a different combination of genes: the gus gene under the control of the act 2 promoter and the ahas (acetohydroxyacid synthase) gene under the control of its promoter from Arabidopsis thaliana. In both, the transgenes were stable during the vegetative phase, but were eliminated during meiosis, the cell division that makes germ cells.

The transgenic bean line contains at least three copies of the transgenes integrated at three separate loci (sites). None of the copies were transferred to the progeny by self-crossing or crosses to untransformed plants. Not a single progeny plant inherited any transgene. This phenomenon was systematically repeated for over two years in plants propagated by grafting ( 20 progenies of more than 300 plants from self-pollination, and 10 progenies of more than 100 plants from crosses to untransformed plants).

Analysis of the host genome flanking the transgene inserts revealed that one integrated plasmid disrupted a ribosomal RNA gene while another was integrated into a sequence with no significant homology to known sequences. The third integrated sequence could not be isolated because it lacked the necessary plasmid sequence. The same phenomenon occurred in the soybean transgenic line.

The instability of the transgenic insert implies that it can jump out and insert at another place in the same genome, or it can transfer horizontally to the genome of cells in all organisms exposed to the GMO.

\section{Horizontal Gene Transfer from GMOs Does Happen}

There is abundant evidence that transgenic DNA can transfer from plant to bacteria in the laboratory, as admitted by the European Food Safety Authority (EFSA) only relatively recently [89], just as it is well-known that transgenic DNA can persist in debris and residues in the soil long after the GM crops have been cultivated. But EFSA, like other regulatory agencies, has persistently denied that horizontal transfer of transgenic DNA can happen in the field or anywhere outside the laboratory. Even though phylogenetic studies have documented rampant cross-kingdom horizontal gene transfers in the course of evolution [71].

It has been demonstrated that while horizontal transfer of similar sequences (by homologous recombination) is the rule in bacteria, the horizontal transfer of non-homologous DNA also occurs at relatively high frequencies when a homologous DNA "anchor sequence" is present, which can be as short as 99 bp [90]. This certainly applies to transgenic DNA, which consists of viral, bacterial and other sequences cobbled together. In a review published in 2004, at least 87 species of naturally transformable bacteria were listed [91] - these are bacteria that can take up and integrate foreign DNA into their genome-representing $2 \%$ of all known species. The authors pointed out that transgenic DNA can spread not only via the roots and plant debris, but also via pollen drift into fields that had never cultivated GM crops. They even developed a bio-monitoring technique for detecting transgenic DNA based on transformation of a competent strain of bacteria that depends on double cross-over (breaking and joining) event between the transgenic DNA and the bacterial chromosome, a 
theoretically much rarer event than a single cross-over. Nevertheless, the bio-monitoring technique is at least as sensitive as a routine polymerase chain reaction (PCR) for detecting minute amounts of specific DNA, indicating that horizontal transfer of transgenic DNA is not a rare event. This conflicts with the irrational conclusion in the same review that [91], "each of the many step involved from the release of intact DNA from a plant cell to integration into a prokaryotic genome has such a low probability that a successful transfer event [is] extremely rare."

Other researchers have confirmed that horizontal transfer of transgenic DNA occurs at readily detectable levels using a similar system [92]. In sterile soil microcosms, transformation was detected using pure plant DNA at $3.6 \times 10^{-8}$ and in ground-up leaves at $2.5 \times 10^{-11}$ transformant per recipient; for non-sterile soil using pure plant DNA, the frequency was $5.5 \times 10^{-11}$ transformant per recipient.

However, it is very likely that transformation frequencies are routinely underestimated, as the overwhelming majority of natural bacteria cannot be cultured in the lab. Using methods that restore function to a green fluorescent protein transgene so the transformed bacteria can be seen without the need to culture and select for them, researchers were able to detect transfer of plant DNA to bacteria directly on the surface of intact leaves as well as on rotting, damaged leaves [93,94]. Rotting and damaged leaves release nutrients that promote bacterial growth, and bacteria that can take up foreign DNA are at their most receptive (competent) state for horizontal gene transfer during exponential growth, thus "opportunistic" hotspots for transfer of plant DNA to bacteria are present in plant material infected with pathogens. The experiment amply confirms that horizontal gene transfer in the field happens at much higher frequencies than previously supposed.

Antibiotic marker genes are routinely used to make GMOs as they offer a convenient way of selecting for cells that have taken up the GM DNA. A major concern is the spread of these antibiotic resistance genes by horizontal gene transfer to bacterial pathogens, making infections untreatable. However, there has been few if any proper study that monitors the spread of antibiotic resistance genes from GM crops released into the environment until recently. A study in China found the antibiotic resistance marker gene, blá, for ampicillin resistance in all six of China's major rivers [95,96]; sequencing confirmed that the gene is a synthetic version derived from a lab and different from the wild type. It is the same as the version present in numerous GM crops released in China commercially or in field trials [96]. The blá gene confers resistance to the most common class of antibiotics called $\beta$-lactams, which includes besides ampicillin (a $\beta$-lactam), the penicillin derivatives (penams), cephalosporins (cephems), monobactams, and carbapenems. The researchers suggested that horizontal gene transfer of genetically engineered plasmids to microbes in the soil or from lactic acid bacteria to human and animal gut microbes is a likely consequence of the pollution of river water, and may underlie the rise in antibiotic resistance in animals as well as humans. This study again provides clear evidence that horizontal gene transfer from GMOs does happen, and very readily so.

Can GM DNA transfer to cells of animals feeding on the GMO? Several studies have documented the survival of DNA in food/feed throughout the intestinal tract in mice and pigs [97,98], in the rumen of sheep [99], and in the rumen and duodenum of cattle [100]. There is also evidence dating from the early 1990s that ingested DNA in food and feed can pass through the intestinal wall and enter the bloodstream (reviewed in [101]).

In the only feeding trial on human volunteers [102], a single meal was given in a milk shake containing GM soya flour with about $3 \times 10^{12}$ copies of the soya genome. The complete $2266 \mathrm{bp}$ of the 
epsps transgene was recovered from the colostomy bag in six out of seven ileostomy subjects, at levels ranging from a high of $10^{11}$ copies $(3.7 \%)$ in one subject to $10^{5}$ copies in another. This is evidence that DNA is not rapidly broken down in the gastrointestinal tract, confirming earlier results from the same research group [103]. Further, in three of the seven ileostomy subjects, about 1 to 3 per million bacteria cultured from the contents of the colostomy bag were positive for the GM soya transgene, showing that horizontal transfer of transgenic DNA had occurred, either before the single meal was taken, as claimed, or else as the result of the single GM soya meal, a possibility that cannot be ruled out [101]. Interestingly, no bacteria were found to have taken up non-transgenic soya DNA, despite the fact that non-transgenic soya DNA is vastly more abundant than the transgenic DNA, and humans have been exposed to non-transgenic soya DNA for millennia. This is the clearest indication that transgenic DNA is much more readily transferred than non-transgenic DNA for reasons given earlier.

The transfer of transgenic DNA demonstrated in the single human trial shows how readily transgenic DNA, including antibiotic resistance genes, can transfer to bacteria, especially in the gastrointestinal tract. The gastrointestinal tract is a hotspot for horizontal gene transfer as successive reviews have made clear [103,104].

Gene transfer from a GM probiotic in the bird gut is much higher than the rates observed by culturing the bacteria on a petri-dish [102], basically because the latter method depends on the diversity of bacteria being able to grow in culture at the same time. Besides, anaerobic bacteria make up $99 \%$ of human gut flora, and these will not grow at all in ordinary culture. Organisms residing in the gastrointestinal tract are thought to be reservoirs of antibiotic resistance and virulence genes. Studies using simulated ileum of the pig gut provided clear evidence that antibiotic resistance could be transmitted between resident and pathogenic members of the Enterobacteriaceae passing through the gut [102].

Gene transfer in the colon has been found in Bacteriodes species. Frequently, the environment of the gut is exposed to low levels of antibiotics used as therapeutic agents, growth promoters, or as contaminants in food. Antibiotics have been shown to stimulate the transfer of mobile genetic elements such as conjugative transposons (jumping genes involved in conjugation, a process whereby bacteria exchange genes via cell contact) and genomes of bacterial viruses which also reside in the bacterial genome. The mouse gastrointestinal tract enabled a shiga toxin 1(Stx1)-encoding phage (bacteria virus) to be transmitted between two E. coli strains and produce infectious virions capable of infecting yet other E. coli strains in the gut.

The rumen is the first "stomach" of cattle, sheep and goats, where high-fibre plant materials are digested by a mixture of micro-organisms, both prokaryotes and eukaryotes, providing a great opportunity for horizontal gene transfer [104]. Transfer of antibiotic resistance in the rumen was first documented in sheep in the 1970s, and since then indirect evidence has mounted for rumen transfer events, with the protozoa in the rumen playing an important role in facilitating gene transfer between bacteria inhabiting the rumen [105].

We have reported $[55,56]$ on how free DNA survives for a considerable period of time in saliva and was able to transfer to Streptococcus gordonii, a natural inhabitant of the mouth; so horizontal gene transfer is likely to start right away in the mouth [106].

All the more so, as foods such as ultra-heat treated milk, cacao drink and tomato juice were found to support horizontal gene transfer when external DNA was added along with bacteria [104]. The highest 
transformation frequencies of $E$. coli occurred in milk, soy drink, tomato and orange juice, and DNA was released and taken up by $E$. coli under food processing conditions.

Evidence is emerging that genomes of higher plants and animals may be softer targets for horizontal gene transfer than genomes of bacteria. We have been warning of this possibility at least since 2001, when experiments in "gene therapy" - making transgenic human cells - were demonstrating how easy it is for transgenic constructs to be taken up by human and animal cells [107]. Similarly, information from transgenic Arabidopsis and rice, with sequenced genomes, and the huge amounts of relic viruses, transposons, retroelements, and chloroplast and mitochondrial DNAs found in these and other sequenced genomes are persuading geneticists that [82]: "nuclear genomes of plants, like those of other eukaryotes, are promiscuous in integrating nonhomologous DNA."

What are the dangers of horizontal transfer of GM DNA? Horizontal transfer of GM DNA into genome of cells per se is harmful [107]: insertion mutations including those leading to cancer, activation of dormant viruses, and recombination with viral sequences in the genome to generate new viruses; all of which have been demonstrated in gene therapy experiments. There are extra dangers from the genes or genetic signals in the GM DNA, and also from the vector used in delivering the transgene(s). These are described below.

\section{Hazards of the CaMV 35S Promoter}

A scientist from EFSA belatedly discovered that major GM crops and products the regulatory agency has been approving for commercial release over the past 20 years contain a potentially dangerous virus gene. The gene - Gene VI - overlaps with the CaMV 35S promoter, the most widely used for driving gene expression in GM crops. This momentous discovery was published [108] in a little known journal, and would have passed unnoticed had it not caught the attention of Independent Science News. A proper retrospective risk assessment on the Gene VI fragment showed that the gene product is toxic to plants probably through, among other things, the inhibition of gene silencing, a necessary function universal to plants and animals (see later); hence it is also likely to be toxic to animals including humans $[109,110]$. They called for all GM crops containing CaMV 35S and similar viral promoters to be withdrawn. This is not the first time that the safety of CaMV 35S promoter is being questioned.

We first raised concerns over the CaMV 35S and similar promoters in a paper published in 1999 [111] when the promoter was discovered to have a recombination hotspot. We argued this would enhance unintended horizontal gene transfer and recombination, and in the process create new viruses or activate old ones, and trigger cancer in animal cells by insertion mutagenesis. The CaMV $35 \mathrm{~S}$ promoter was known to be highly promiscuous in being able to function in most if not all species across the living world (including human cells, as it turned out). To make matters worse, many synthetic versions of the promoter have been constructed with additional enhancers for gene expression and sequences from other sources, all of which increase its instability (tendency to fragment) as well as its ability to drive inappropriate gene expression. (We also reported the overlap of the $35 \mathrm{~S}$ promoter with Gene VI, so this knowledge must have been widely known, although its safety implications were not obvious, at least to us.) As a precautionary measure, we strongly recommended that all transgenic crops containing CaMV 35S or similar promoters should be immediately withdrawn from commercial production or open field trials. 
Our first paper brought a swift reaction. Within two days of its being published online, at least nine critiques, including one from Monsanto, were posted on a website funded by the biotech industry and widely circulated on the internet. The critiques varied in tone from moderately polite to outright abusive. We wrote a detailed rebuttal, which was likewise circulated and posted to the same website, and have not received any replies from our critics since. But in January 2000, Nature Biotechnology published a distorted, one-sided and offensive account of our paper, concentrating on the criticisms and ignoring our rebuttal completely, which we published in the same journal that carried the first paper [112].

It is significant but sad that regulators have denied any risk posed by gene VI in exactly the same way they argued against the dangers posed by the recombination hotspot in the CaMV 35S promoter. The first objection is that humans have been eating the CaMV for millennia without ill effects (if indeed people ate virus-infected vegetables); the second is that the CaMV $35 \mathrm{~S}$ promoter is only active in plants and certainly not in animal or human cells.

Our rebuttal to the first objection is that the intact CaMV, consisting of the CaMV genome wrapped in its protein coat, even if eaten, is not infectious for human beings or for other non-susceptible animals and plants; for it is the coat that determines host susceptibility in the first instance. However, the naked or free viral genomes (and parts thereof) are known to be more infectious and have a wider host-range than the intact virus. Furthermore, the synthetic CaMV $35 \mathrm{~S}$ promoters are very different from the natural promoters, often with extra sequences added, and are both much more aggressive as promoters driving inappropriate gene expression as well as more prone to fragment and recombine.

The second objection - that CaMV 35S is not active in animals and human cells - is simply false as we discovered in the scientific literature dating back to 1989, and pointed this out in a third report [113]. The CaMV 35S promoter supported high levels of reporter gene expression in mature Xenopus oocytes [114] and gave very efficient transcription in extracts of nuclei from HeLa cells (a human cell line) [115].

What of our original concern over the CaMV 35S promoter activating viruses in host genomes? There is new evidence suggesting that the CaMV 35S promoter may enhance the multiplication of disease-associated viruses including HIV and cytomegalovirus through the induction of proteins required for transcription of the viruses [116,117]. These known hazards of the CaMV 35S promoter are in addition to those due to gene VI; which fully justifies our original recommendation for a total recall of the affected GM crops.

\section{Hazards of the Agrobacterium Vector}

In 2010, scientists at Bristol University in the UK announced the [118] "discovery of a previously unknown route" whereby "GM genes may escape into the natural environment".

The "escape" referred to is horizontal gene transfer. The researchers showed that plant wounds created by insect bites, abrasion and other mechanical damage, are hotspots for gene trafficking due to the wound hormones produced by the plant. Under such circumstances, the soil bacterium Agrobacterium tumefaciens, which causes crown gall disease in plants, could expand its host range to infect fungi, and insert foreign genes into the fungi's genome [119]. This has large implications on the 
safety of GMOs already widely released into the environment, according to the authors. It turns out that their discovery is not new.

A. tumefaciens causes crown-gall disease in plants, a tumour-like growth or gall on the infected plant, accompanied by the transfer of a DNA segment (T-DNA) from the tumour-inducing (Ti) plasmid of the bacterium. It is probably unique among natural plant pathogens in carrying out trans-kingdom horizontal gene transfer during an infection. And it is this ability that has been widely exploited for creating GM crops. But this was a big mistake (see later).

In the 1990s, it was shown that the range of organisms transformed by Agrobacterium could be extended if the wound hormone acetosyringone was used to induce the virulence (disease causing) system.

The researchers at Bristol University reasoned that as A. tumefaciens is a soil-dwelling pathogen that often infects plants through wounds, it is conceivable that the bacterium could encounter numerous species of microorganisms, including pathogenic fungi that use the same method to gain entry into the plant. The wound sites are likely to be exuding wound hormones such as acetosyringone, so the bacteria are primed for T-DNA transfer to the other species.

For their investigations, they used the wilt-causing fungus Verticillium albo-atrum, a strong candidate for encounters with Agrobacterium in the plant, as it has a similarly wide host range, infecting both root and crown. Previous lab experiments have shown that $V$. albo-atrum cannot be transformed by Agrobacterium in the absence of acetosyringone. So, if it is presented with Agrobacterium on plant tissue, and transformation does occur, it must be the plant that supplies the wound hormone.

Successful transformants of $V$. albo-atrum were obtained at high frequencies in every kind of plant tissue: 2 out of 17 potato slices, 1 out of 15 carrot slices; 14 out of 42 dishes each with 3-5 leaf pieces, and 10 out of 31 stem sections. The transformants were confirmed by molecular genetic analyses.

The researchers concluded [119]: "This work therefore raises interesting questions about whether the host range of A. tumefaciens in nature is greater than just plants. It is possible that evidence of such events could be looked for retrospectively in the increasing number of genome sequences becoming available....".

"In addition, the result may well have implications for the risk assessment of GM plants generated via Agrobacterium-mediated transformation, as Agrobacterium can survive within plant tissue through transformation and tissue culture and can therefore be found within regenerated transgenic plants...".

This is, if anything, an understatement of a serious risk that has been known almost since the first release of Agrobacterium-transformed GMOs into the environment.

By the late 1990s, the Agrobacterium vector system became very widely used, and many GM crops created were commercially released. Scientists at the Kinsealy Research and Development Centre in Dublin, Ireland, and the Scottish Crop Research Institute in Dundee, Scotland, were concerned that the inserted genes in plants would spread to wild populations by cross-pollination or by horizontal gene transfer to unrelated species, which was by then well-documented in the scientific literature.

The researchers considered it "imperative" to address the risk posed by using Agrobacterium as a tool in genetic engineering [120,121], given its ability to transfer genes to other plants.

The transformation procedure involves inoculating the cells or tissue explants with the Agrobacterium vector system (consisting of the genetically modified Agrobacterium and its binary vector) 
and co-cultivation the plant cells and bacteria for a short period, followed by the elimination of the bacteria with antibiotics.

However, if all the bacteria were not eliminated, then "release of these plants may also result in release of the Agrobacterium (with the foreign genes)", which will serve as a vehicle for further gene escape, at least to other Agrobacterium strains naturally present in the soil in the first instance.

Although various antibiotics have been used to eliminate Agrobacterium following transformation, the researchers stated that "very few authors actually test to ensure that the antibiotics succeed."

Moreover, the Agrobacterium can remain latent within the plant tissue. So putting transgenic plant material into culture medium without antibiotics and finding no Agrobacterium, is not a guarantee that the transgenic plant is free of it, as was often assumed.

In their study, they investigated the ability of antibiotics to eliminate Agrobacterium tumefaciens after transformation in three model systems: Brassica (mustard), Solanum (potato), and Rubus (raspberry). The antibiotics carbenicillin, cefataxime and ticaracillin were used respectively to eliminate the bacterium at four times the minimum bactericidal concentration, as recommended. They found that none of the antibiotic succeeded in eliminating Agrobacterium.

The contamination levels increased from 12 to 16 weeks to such an extent that transgenic Solanum cultures senesced and died. Contamination in shoot material decreased over 16 to 24 weeks possibly because only the apical node was used in further culture, but even that did not eliminate Agrobacterium from all the samples; 24\% remained contaminated at 24 weeks.

The binary vector was also present under non-selective conditions up to 6 months after transformation, where approximately $50 \%$ of contaminated material still harboured bacterial cells with the binary vector at high levels of about $10^{7}$ colony forming units per gram. The researchers pointed out: "Here is where the possibility of gene escape arises. The presence of the disarmed Agrobacterium in the tissue would not be a problem if the binary vector had been lost, but now its survival and spread are real possibilities." The binary vector contains the foreign genes as well as antibiotic resistance marker gene(s).

There is no limit to the foreign genes that can be inserted into the binary vector. A few years earlier, a research group in Israel had inserted a viroid that causes disease in citrus fruits into the disarmed Ti plasmid of Agrobacterium and used that to infect and transform several plant species including tomato (Lycopersicon esculentum) Gynura aurantiaca, avocado (Persea americana), and grapefruit (Citrus paradisi) grafted on Troyer citrange (Pancirus trifoliate x C. sinensis) [122]. Extracts prepared from tissues of the infected plants 38-90 days after inoculation were plated on selective media and found to contain large amounts of the engineered bacteria.

The researchers warned of [122] "newly formed combinations of persistently transmitted viruses" coupled with "the opportunistic and systemically moving Agrobacterium vector infectious to a wide host range might eventually cause infection and damage to crop plants or natural vegetation" that are "not presently visited by the traditional vectors of the virus disease".

In other words, Agrobacterium persisting in transgenic plants released into the environment has the potential to spread newly created viral diseases, and to plants that normally would not be infected by the disease agents. At the time, the researchers did not know that Agrobacterium would also infect animals and humans, and could spread new diseases to them as well (see below). 
There is no evidence the early warnings have been taken on board. Agrobacterium has since been shown to transform at least 80 different non-plant species including yeasts and other fungi, algae, mammalian and human cells, also the gram positive bacterium Streptomyces lividans. A review published in 2008 stated [123]: "Future research has to show whether Agrobacterium-mediated transformation contributed to horizontal gene transfer between microorganisms in the rhizosphere".

We have repeatedly drawn attention to this possibility, most recently in 2011 [70] and before that, in 2010 [69] and in 2008 [124]; the danger is even greater than envisaged in the early warnings of the $1990 \mathrm{~s}$.

In the gene transfer system based on $A$. tumefaciens, foreign genes are spliced into the mini-T-DNA binary that ends up integrated into the genome of the plant cell. But further investigations revealed that the process whereby Agrobacterium injects T-DNA into plant cells strongly resembles conjugation, the natural mating process between bacterial cells; and the crucial genetic signals are interchangeable [125].

Conjugation, mediated by certain bacterial plasmids requires a sequence called the origin of transfer (oriT) on the DNA transferred. All the other functions can be supplied from unlinked sources, referred to as "trans-acting functions" (or tra).

It transpired that the left and right borders of the T-DNA are similar to oriT, and can be replaced by it. Further, the disarmed T-DNA, lacking the trans-acting functions (virulence genes that contribute to disease), can be helped by similar genes belonging to many other pathogenic bacteria.

That means transgenic plants created by the Agrobacterium binary vector system have a ready route for horizontal gene escape, via Agrobacterium, helped by the ordinary conjugative mechanisms of many other bacteria that cause diseases, which are present in the environment. I first pointed this out [126] in reviewing a book on horizontal gene transfer published in 2002 [71]. The book contained all the key information on the similarity between Agrobacterium's gene transfer system and bacterial conjugation but still failed to sound the warning.

Agrobacterium not only transfers genes into plant cells; there is possibility for retrotransfer of DNA from the plant cell to Agrobacterium [127]. High rates of gene transfer are associated with the plant root system and the germinating seed, where conjugation is most likely [128].

Finally, Agrobacterium attaches to and genetically transforms several human cell lines [129,130]. In stably transformed HeLa cells (a human cell line derived originally from a cancer patient), the integration of $T-D N A$ occurred at the right border, exactly as would happen when it is transferred into a plant cell genome. This suggests that Agrobacterium transforms human cells by a mechanism similar to that which it uses for transforming plants cells.

Cummins commented [131]: "The paper shows that human cancer cells along with neurons and kidney cells were transformed with the Agrobacterium T-DNA. Such observations should raise alarm for those who use Agrobacterium in the laboratory".

Cummins could have warned of exposure to Agrobacterium via ordinary soil, especially those contaminated with genetically modified plant debris and Agrobacterium.

The possibility that Agrobacterium is a vehicle for horizontal spread of transgenic DNA and the dangers of creating new pathogens remains unresolved to this day.

In 2008, Agrobacterium was linked to the outbreak of a strange disease. 


\section{Agrobacterium and Morgellons Disease}

The Centers for Disease Control (CDC) in the United States launched an investigation on "Morgellons disease" in January 2008 [131,132] (see [133]) after receiving thousands of complaints from people with this bewildering condition described as an unexplained skin condition with a reported range of symptoms including crawling, biting and stinging sensations; granules, threads, fibres, or black speck-like materials on or beneath the skin, and/or skin lesions; in some cases also fatigue, mental confusion, short term memory loss, joint pain, and changes in visions.

Morgellons disease first became known in 2001, when Mary Leitao created a web site describing the illness in her young son, which she named after a 17th century medical study in France describing similar symptoms. Until then, people with Morgellons disease have been diagnosed as cases of "delusional parasitosis", in which the symptoms are deemed entirely imaginary, and lesions allegedly due to self-inflicted wounds.

In a paper [134] published in 2006, researchers from the Morgellons Research Foundation (which no longer exists) identified the states of California, Texas and Florida as having the highest number of cases of Morgellons disease in the United States, but all 50 US states and 15 other nations, including Canada, the UK, Australia, and the Netherlands, have reported cases of the disease. The two main occupational groups reporting symptoms are nurses and teachers, with nurses outnumbering teachers three to one. The risk factor common to both groups was suspected to be a transmitted infectious agent. Contact with soil or waste products appears to be associated with the disease. Cases have been reported in cats and dogs, as well as horses. The list of people registered with Morgellons disease totalled 12,106 worldwide, as recorded by Morgellons Research Foundation on 12 April 2008. CDC's investigation was to be carried out in conjunction with Kaiser Permanente's Northern California Division of Research and the US Armed Forces Institute of Pathology.

What finally prompted CDC to investigate the disease was probably the discovery in January 2007 of Agrobacterium DNA in fibres of skin biopsies taken from Morgellons disease patients. The work was carried out by a team that included Vitaly Citovsky, a professor of molecular and cell biology at Stony Brook University in New York (SUNY), the very scientist who discovered Agrobacterium can transfer genes to human cells [129]. The team took scanning electron microscope pictures of the fibres in or extruding from the skin of patients suffering from Morgellons disease, confirming that they are unlike any ordinary natural or synthetic fibres.

The team also analysed patients for Agrobacterium DNA. Skin biopsy samples from Morgellons patients were subjected to high-stringency polymerase chain reaction (PCR) tests for genes encoded by the Agrobacterium chromosome and for Agrobacterium virulence (vir) genes and T-DNA on its Ti plasmid. They found that "all Morgellons patients screened to date have tested positive for the presence of Agrobacterium, whereas this microorganism has not been detected in any of the samples derived from the control, healthy individuals." Their preliminary conclusion was that "Agrobacterium may be involved in the etiology and/or progression" of Morgellons disease.

The unpublished findings, including electron micrographs, were posted on a website in January 2007 that no longer exists. A brief publication in Journal of Investigative Medicine reported the finding of Agrobacterium genes in two Morgellons patients and the authors including Citovsky explained why they looked for Agrobacterium [135]: "Morgellons skin fibers appear to contain 
cellulose. This observation indicates possible involvement of pathogenic Agrobacterium, which is known to produce cellulose fibers at infection sites within host tissues."

We wrote a report on the possible connection between the use of Agrobacterium in genetic modification and the widespread release of GM crops contaminated with genetically modified Agrobacterium and Morgellons disease [133], which was sent to the CDC, asking the CDC to clarify the role of Agrobacterium in the aetiology of Morgellons disease as a matter of urgency.

In 2012, after a long delay, the CDC published its verdict [136]: "No common underlying medical condition or infectious source was identified, similar to more commonly recognized conditions such as delusional infestation." No investigations were done on the Agrobacterium connection; and the list of authors did not include Citovsky or his associates. The case is far from closed.

\section{RNA Interference and Double-Stranded RNA}

Most commercially grown GM crops are engineered to produce foreign proteins, but new ones are increasingly engineered to produce RNA of a special kind - double-stranded RNA (dsRNA) — that aims to interfere with the expression of a specific gene, usually to silence the gene [137]. The ability of dsRNA to interfere with gene expression was known since the 1980s; and the biochemistry of the phenomenon-referred to as RNA interference (RNAi) - was worked out in the roundworm Caenorhabditis elegans in the late 1990s [138]. Since then, the same RNAi pathway has been identified in practically all plant and animal kingdoms, and is part of the organism's defence against foreign nucleic acids including viruses.

DsRNA includes siRNA (short-inhibitory RNA), miRNA (microRNA), shRNA (short hairpin RNA) etc., all intermediates leading to RNA interference of protein synthesis. This can happen at transcription, or at translation. Typically, dsRNA originates from a long RNA molecule with stretches of complementary base sequences that base pair to form a stem ending in a non-base-paired loop. This stem-loop structure is then processed into a shorter dsRNA, and one strand, the guide strand does the job of interfering. It binds to a mRNA (messenger RNA) molecule in the cytoplasm by complementary base-pairing to prevent the mRNA from being translated into protein. Alternatively, the guide strand targets and chemically modifies DNA sequences in the nucleus by adding methyl groups to the DNA, and cause modification of histone proteins associated with the DNA. The nuclear pathway is known to inhibit transcription and to seed the formation of heterochromatin, an inactive, non-transcribed region of chromosomes.

Interestingly, the gene silencing effect of dsRNA can become inherited (either indefinitely, or through two or more generations) in cells and organisms that are not genetically modified, but simply exposed to the dsRNA for a period of time. It can happen via methyl groups added to the DNA, or the modification of histones [139,140] or perhaps through RNA-dependent RNA polymerase that can amplify and perpetuate the dsRNA [141] without changing the base sequence of the DNA in the genome. This is another example of the inheritance of acquired characters now known to occur through many different mechanisms (see [142] and other articles in the series) that makes genetic modification all the more hazardous (more on this later).

DsRNA genetic modification has large implications on safety based on what is already known [143]: dsRNA is stable, it resists digestion and can enter the bloodstream; its role in modifying gene 
expression is universal to higher plants and animals and acts across kingdoms; toxicity to animals have been amply demonstrated and exploited in targeting pests; although the intended target is a specific gene, many off-target effects have been identified; finally, plant dsRNA has been found circulating in the human bloodstream where it can be taken up into cells and tissues to interfere with the expression of genes. Consequently, animals including human beings eating the GM food containing dsRNA could well be harmed.

The dangers are real. Researchers in China showed that miRNA from food can circulate in the human blood stream and turn genes off in the human body [144,145]. They demonstrated that dsRNAs can survive digestion and be taken up in the circulatory system via the gastrointestinal tract. These plant-derived miRNA silenced a gene in human tissue culture cells, and in mouse liver, small intestine and lung. A survey of existing data of small RNA molecules from human blood and tissues sources, farm animals and insects confirmed that regulatory RNAs from plants can be found in animals including humans [145]. Thus, new dsRNA species in GM foods may be taken up by the animal cells to silence genes inappropriately.

Gene-silencing depends on complementary base pairing for short sequences - 21 bases at most, but could be as few as seven for miRNA - and there could be similar sequences all over the same genome and in genomes of other species. In particular, many miRNA target regulatory sequences of genes that are likely to be common to sets of genes expressed together [146] in certain tissues and cells. Worse yet, the matching need not be precise. Off-target effects are already well-known in gene therapy applications [147].

Over the past decade, investigations have produced a set of "canonical rules" governing the interaction between miRNA and their target mRNA, but many exceptions to the rules have also been found.

Recently, researchers used a new technique to capture all the miRNAs bound to their targets by cross-linking them and sequencing the base-paired miRNA-target RNA duplexes. They found that the exceptions far outnumber the rule-based interactions [148,149]. Moreover, the results have been obtained in one cell type, human embryonic kidney cells, grown in culture. The report closed with the comment [147]: "More generally, the spectrum of miRNA-mRNA interactions is expected to rapidly change during differentiation and viral infection and following metabolic shifts or environmental insults". In other words, it is well-nigh impossible to predict or control off-target effects, as they vary according to the cells and tissues involved and their precise states. In terms of biosemiotics [5], the mapping from $\mathrm{O}$ to $\mathrm{S}$, controlled or mediated by $\pi$ is completely context-dependent and in an extremely fine-grained way, differing among cell types and their microenvironments as well as the environment experienced by the whole organism in the course of development. This is what one has come to expect in the new science of the fluid and responsive genome in which both DNA and RNA are actively involved in moment to moment biological functions.

A worst case scenario of toxic dsRNA came from a gene "therapy" experiment in mice reported in 2006, which killed more than 150 animals [150,151]. The technique-hailed as 2002's "breakthrough of the year" in "precision" gene therapy - was found to have many off-target effects a year later [152,153]. Researchers were already finding dozens of genes affected by a single siRNA.

A comparison between the DNA sequence of the human genome and a DNA sequence from the wheat SBE1 gene provided to the database Genbank by CSIRO, for which a GM wheat based on dsRNA gene silencing has been created, identified four perfect matches of 21 nucleotides and another 
13 nucleotide stretch match within a wheat gene sequence of just 536 nucleotides [154]. This does not include comparisons of secondary unintended dsRNAs that may be induced in the GM plant, as indeed, in any GMO, including those not explicitly engineered to create dsRNA, nor the many mismatches that can give rise to a plethora of off-target effects under different environmental conditions in different cells and tissues. But this is not the end of the story.

\section{The Nucleic Acids Intercom}

The conventional and especially the popular view of DNA is that it sits within the nucleus of the cell, somewhat static and metabolically inert, except during replication in dividing cells, or in repair when damaged, for example, by ultraviolet light. RNA, the other nucleic acid, has the job of transmitting the genetic message written in the DNA to the rest of the cell. RNA consists of faithful complementary copies of stretches of DNA that, after extensive processing, are exported outside the nucleus to the cytoplasm, where they form different parts of the necessary machinery to translate the messenger RNAs into proteins. And proteins are responsible for all the downstream biological functions. Consequently, knowing the sequence of DNA in the genome will decode the secret of life, will tell you how the organism, the human being, is constructed. That was how the human genome project as well as genetic modification was sold to the public [8].

Nothing could be further from the truth even before the human genome was conceived. The most important contribution of the human genome project to the advancement of science is to put to rest the genetic determinist ideology that made the project seem so compelling ([155]. It has conspicuously failed to deliver even promises to identify the genes that predispose us to common diseases [156], hence the problem of "missing heritability" [157,158] and other attributes such as IQ or intelligence $[159,160]$; let alone how to construct a human being. Instead, environmental, epigenetic effects that mark and change genes across generations have come onto centre stage [142].

Some of us knew that genetic determinism was already untenable at least since the early 1980s when recombinant DNA (genetic engineering) technology enabled geneticists to scrutinize the genome in fine molecular detail and discovered to their astonishment what they called "the fluid genome" [8,9,15] (see earlier). Nevertheless, it is still amazing how dynamic and responsive the genetic material is, and how utterly entangled with everyday "downstream" biological functions; no wonder it is impossible to pin down the genes predisposing us to diseases and other human attributes [156-160].

RNA not only acts as messenger RNAs, ribosomal RNAs and transfer RNAs for making proteins, it also acts as enzymes - ribozymes - that cut and join RNAs to make new ones that are not encoded in the genome, it targets specific mRNA for cleavage, and is the active enzyme of the ribosome that joins amino acids together to make proteins [161]. RNA is now known to regulate gene expression through thousands of miRNAs in RNA interference universal to plants and animals (see previous section) (Bacteria and Archaebacteria too, have RNAi, but it works differently from eukaryotes [162]). MiRNAs are part of the nucleic acid intercommunication system of the body [163].

\subsection{Darwin's Pangenesis Is Precursor to Nucleic Acid Intercom}

The nucleic acid intercom has been rediscovered several times since Darwin proposed his theory of pangenesis — to account for heredity including the inheritance of acquired characters [164,165]—and is 
really the precursor to the nucleic acid intercom. Darwin suggested in 1868 that all cells of an organism shed minute particles, gemmules, which circulate throughout the body and are passed on to the next generation through the germ cells, thereby transmitting the characteristics of the parents to their offspring. And if the cells of the parents undergo changes during their life time, those changes would also be transmitted to the offspring, resulting in the inheritance of acquired characters.

Darwin's cousin Francis Galton designed a series of blood transfusion experiments on rabbits with different pigments to test the theory of pangenesis, or at any rate, to test if gemmules existed; but found no evidence for them (probably because the volume of blood transfused was too small), and the theory was largely abandoned.

Within the past decade, geneticists have discovered substantial amounts of nucleic acids circulating in the bloodstream that are taken up by cells and transported to the nucleus, where they could be integrated into the cells' genome [163-165]. These nucleic acids appear very much like Darwin's gemmules. Many experiments subsequent to those carried out by Galton, on grafting in plants and transfusion in animals, showed that heritable characteristics could be transferred between organisms in the form of nucleic acids.

Furthermore, germ cells too can take up circulating nucleic acids, because there is really no "Weismann's barrier" separating somatic from germ cells (reviewed in [8]). Cytoplasmic/maternal inheritance is well-known; but it turns out that sperms are very adept at taking up nucleic acids and transferring them into egg cells at fertilization. This process is so well-established that it is referred to as sperm-mediated gene transfer [166,167]; and applies not only to DNA, but also RNA. RNA sequences are reverse transcribed into complementary DNA (cDNA) sequences. The nucleic acids are delivered to the egg at fertilization, and inherited by the developing embryo in mosaic fashion; the foreign DNA being maintained stably as episomes (extrachromosomal DNA), but also occasionally integrated into the cell genome. Sperm-mediated gene transfer can be made to happen easily by exposing sperm cells to nucleic acids, but it has also been observed to happen in vivo [167,168], where either parent can transmit a mutant trait to an offspring that has two wild type copies of the gene, and hence not supposed to exhibit the mutant trait.

Pangenesis was expurgated from the mainstream neo-Darwinian account of evolution, as was any suggestion that circulating nucleic acids serve as intercommunication between cells and tissues in the same organism and between different organisms, or that they could be transmitted to the next generation.

\subsection{Nucleic Acids Trafficked between Cells}

Both RNA and DNA are actually trafficked between cells, sent out from cells in overlapping but distinct vehicles to inform and transform other cells. Distinct populations of nucleic acids are exported from different cells in various conditions of health and disease, so much so that they are offering new opportunities for diagnosis. There is also evidence that nucleic acids exported by cancer cells both condition the body to accept cancer cells and spread cancer to other cells. Genetically modified nucleic acids, therefore, can take advantage of the system to enter and transform cells or do harm in other ways. There can be no doubt that this can happen; the ease with which nucleic acids are taken up by cells has been widely exploited in experiments in "gene therapy" since the 1990s [107]. 
The best characterized vehicles for intercellular nucleic acid trafficking are exosomes [169]. Exosomes are membrane-bound vesicles (40-100 nm diameter) assembled in a membrane bound multivesicular body (MVB) inside the cell [170]. The membrane of the MVB invaginates to form the vesicles that are packed with enzymes, cytokines (cell-cell communication molecules of the immune system), nucleic acids and other signalling compounds. In response to stimuli, the MVB fuses with the plasma membrane and the vesicles are released as exosomes into the extracellular space where they can interact with neighbouring cells or other more distant cells and induce changes in their state through the transfer of new receptor molecules or genetic material.

Exosomes are released in vitro by a wide range of cells in the blood and bone marrow as well as cancer cells. In vivo, exosomes have been isolated and characterized in practically all body fluids plasma, urine, saliva, cerebrospinal fluid, amniotic and synovial fluids.

Exosomes from different sources have a common set of proteins that regulate membrane cytoskeleton dynamics and membrane fusion; they also have a specific molecular repertoire that varies according to the cell type and conditions from which they originate. They are enriched in specific nucleic acids, in particular miRNAs and RNAs generally in complexes with proteins. Exosomes are now considered an integral part of the intercellular communication system for immune modulation, as for example during pregnancy, to enable the mother's immune system to tolerate antigens from the foetus, or during oxidative stress, to increase the ability of other cells to withstand oxidative stress. However, cancer cells also make use of the same communication system to spread around the body.

DNA is known to be released in apoptotic bodies (membrane-bound vesicles containing fragmented DNA resulting from programmed cell death), which can be phagocytosed (engulfed) and transported into the nucleus of recipient cells for expression and integration into the genome (see [159]).

Apoptotic bodies derived from tumour cells induce foci (centres of malignancy) in p53-deficient fibroblast cultures in vitro and tumours in animals. Whole chromosomes or fragments are transferred by the phagocytosis pathway and integrated into the genome [171]. Horizontal gene transfer between cells may be important during tumour progression.

A further mechanism of horizontal DNA transfer has been suggested by studies in autoimmune disease [172]. The antimicrobial peptide LL-37, widely expressed in epithelia, bone marrow, and the genitourinary tract of humans, forms stable complexes with DNA and translocates extracellular DNA to the nucleus. LL-37-mediated delivery of self DNA may be an early event in autoimmune disease. The ability of LL-37 to transfer DNA across the plasma membrane is a shared property within the growing family of "cell-penetrating peptides".

Circulating DNA in cancer patients has many characteristics in common with the DNA of their tumours, and is suspected of being derived from apoptotic bodies of cancer cells. Furthermore, elevated concentration of circulating DNA per se appears indicative of disease states, whether it is cancer, systemic lupus erthyematosus, rheumatoid arthritis, glomerulonephritis, pancreatic, hepatitis, inflammatory bowel disease, etc [173].

There is current debate as to whether circulating DNA is solely derived from dead cells or whether they are actively secreted by living cells (see [163]). It has been pointed out that the DNA circulating in healthy individuals simply do not have the characteristics of DNA from apoptotic or other dead cells, and any apoptotic DNA released from dead cells are immediately cleared and broken down by phagocytic cells nearby before it can reach the blood stream. Only in disease states when cells die in 
great numbers exceeding the capacity of phagocytic cells to clear the DNA do apoptotic bodies reach the circulation [171]. Thus, in cell cultures with no dead cells, DNA is nevertheless actively secreted into the medium until a certain external concentration is reached. Replacing the medium leads to further secretion until the external equilibrium concentration is restored.

In fact, the active release of DNA from living cells has been known for at least 50 years, leading to the hypothesis that such DNA could be acting as a messenger (see [174,175] and references therein). The main part of the DNA circulating in plasma and serum comes from active release of newly synthesized DNA by living cells. The released DNA is associated with RNA and a glycolipoprotein complex that in bacteria contains a DNA-dependent RNA polymerase, and in higher organisms, also a DNA-dependent DNA polymerase. Alu repeat sequences (transposons) are overrepresented compared to unique gene sequences. The spontaneously released DNA has a lower molecular weight than the typical genomic DNA. Both dividing and non-dividing cells release DNA, but not cells that are damaged or dying. Such release of DNA also takes place in bacteria, and cells of amphibians, birds, human, mammals, and plants. This DNA complex can be readily taken up by other cells where it can become integrated into the chromatin and expressed, both in vitro and in vivo.

High through-put parallel DNA sequencing of total circulating DNA from the serum of 51 healthy humans compared with 4 genomic DNA showed that the profile of circulating DNA resembled normal genomic DNA with the following exceptions [176]. Chromosome 19 sequences are under-represented; chromosome 19 contains most genes and has the highest amount of Alu elements. Alu sequences, are over-represented, accounting for $11.4 \pm 0.4 \%$ in circulating DNA samples compared to $8.5 \pm 0.8 \%$ in the genomic samples; while L1 and L2 long interspersed nuclear elements (LINEs) are under-represented, accounting for $19 \%$ in serum DNA samples compared with $22.8 \%$ in genomic samples. Also notable were the relatively large individual variations of circulating DNA for coding sequences, which ranged from 0.78 to 1.4 times genomic sequences; untranslated regulatory sequences, ranging from 0.58 to 1.3 times genomic sequences, and pseudogenes (relict genes previously believed to be no longer active) ranging from 0.85 to 1.15 times genomic sequences. The researchers conclude that non-specific release (due to cell death) is not the sole origin for circulating DNA.

\subsection{Homologous Recombination by Uptake of Circulating DNA}

It has been suggested that circulating DNA takes part in homologous recombination with genomic DNA, and that this process can correct mutations as well as induce genetic changes, with the external DNA fragments serving as reference molecules [177]. The team of researchers from Novosibirsk State University in Russia had used total genomic DNA preparations added to the culture medium to "reprogramme" cancer cells to normal cells. They also injected fragmented wild type rat DNA into rats with diabetes caused by hereditary vasopressin deficiency, resulting in rapid improvement of the animals' physiological condition. Injection of fragmented wild-type mouse genomic DNA into mice lethally irradiated with ionising radiation saved the mice and accelerated the recovery of animals treated with a chemotherapeutic mutagen cyclophosphamide. They postulated that small genomic DNA fragments entered the cell nuclei and eliminated the mutations. In a later report, the team showed that short wild type human genomic DNA fragments added to the culture medium of proliferating human breast cancer cells entered the cell nuclei and repaired the extended $47 \mathrm{bp}$ deletion in their 
CASP3 gene [178]. The fragments, 200-3000 bp, were obtained by sonicating human placental DNA from a healthy consenting donor, followed by nuclease digestion. The fragments were labelled with radioactive ${ }^{32} \mathrm{P}$ isotope and added to the culture medium, and the time course of repair of the deletion followed by PCR with primers flanking the deletion in the DNA isolated from the cells. The wild-type product is $125 \mathrm{bp}$ while the mutant product is $78 \mathrm{bp}$. In the first experiment, cells treated for 6 and 12 days showed wild-type: mutant product in a ratio of $1: 1$, indicating that some $50 \%$ of the mutant genes had been repaired. In a second experiment monitored at 5 and 40 days, the team detected wild-type gene repair at 5 days, but at 40 days, the wild-type product greatly exceeded the mutant product.

The result obtained was remarkable considering that the correct CASP3 gene sequence was only one of millions of other genomic sequences in the random mixture of the genomic DNA fragments used. The researchers mentioned the possible risk [178] "of introducing mutations or causing a new disease if the DNA used for treatment contains such mutations." The same applies to the potential danger of extraneous transgenic DNA that may get integrated into the genome of host cells; considering that transgenic DNA may be especially invasive, and could integrate even through non-homologous recombination.

\section{Conclusions}

The rationale and impetus for genetic engineering and genetic modification was the "central dogma" of molecular biology that assumed DNA carries all the instructions for making an organism. The mechanistic fallacy is inherent in the very term "genetic engineering", for it goes against the grain of the fluid and responsive genome that already emerged since the early 1980s.

Instead of linear causal chains leading from DNA to RNA to protein and downstream biological functions, complex feed-forward and feed-back cycles interconnect organism and environment at all levels, marking and changing RNA and DNA down the generations.

In order to survive, the organism needs to engage in natural genetic modification in real time, an exquisitely precise molecular dance of life with RNA and DNA responding to and participating fully in "downstream" biological functions. Artificial genetic modification interferes fundamentally with the natural process and it is well-nigh impossible to avoid doing so. In addition, the artificial GM constructs are invasive and contain hazardous elements that can take over the natural mechanisms for transfer into cells. In the scheme of biosemiotics [20], GM nucleic acids are alien symbols with the ability to scramble the biosemantics of a coherent, healthy organism; the effects of which can be passed down to future generations, propagating to the wider ecosystem, thereby maximising biosemiotic entropy.

\section{Acknowledgments}

I am very grateful to John Oller for inviting me to contribute to the special issue on biosemiotics, and for suggestions that substantially improved this manuscript. 


\section{Conflicts of Interest}

The author declares no conflict of interest.

\section{References}

1. Bruening, G.; Lyons, J.M. The case of the FLAVR SAVR tomato. Calif. Agric. 2000, 54, 6-7.

2. Crick, F.H.C. On protein synthesis. Symp. Soc. Exp. Biol. 1958, 12, 139-163.

3. Crick, F. Central dogma of molecular biology. Nature 1970, 227, 561-563.

4. Watson, J.D.; Crick, F. A structure for deoxyribose nucleic acid. Nature 1953, 171, 737-738.

5. Oller, J.W., Jr. The antithesis of entropy: Biosemiotic communication from genetics to human language with special emphasis on the immune systems. Entropy 2010, 12, 631-705.

6. Gryder, B.; Nelson, C.; Shepard, S. Biosemiotic entropy of the genome: mutations and epigenetic imbalances resulting in cancer. Entropy 2013, 15, 234-261.

7. Samsel, A.; Seneff, S. Glyphosate's suppression of cytochrome P450 enzymes and amino acid biosynthesis by the gut microbiome: Pathways to modern diseases. Entropy 2013, 15, 1416-1463.

8. Ho, M.W. Genetic Engineering Dream of Nightmare? The Brave New World of Bad Science and Big Business, 3rd ed.; Gateway books: New York, NY, USA, 2007.

9. Dover, G.; Flavell, D. Genome Evolution; Oxford University Press: Oxford, UK, 1982.

10. Ho, M.W. Evolution by process, not by consequence: Implicationsof the new molecular genetics for development and evolution. Int. J. Comp. Psychol. 1987, 1, 3-27.

11. Pollard, J.W. The Fluid Genome and Evolution. In Evolutionary Processes and Metaphors; Ho, M.W., Fox, S., Eds.; Wiley: London, UK, 1988; pp. 63-84.

12. Shapiro, J. Genome organization, natural genetic engineerging and adaptive mutation. Trends Genet. 1997, 13, 98-104.

13. Jablonka, E.; Lamb, M. Epigenetic Inheritance and Evolution, the Lamarckian Dimension; Oxford University Press: Oxford, UK, 1995.

14. Ho, M.W. Death of the central dogma. Sci. Soc. 2004, 24, 4.

15. Ho, M.W. Living with the Fluid Genome. Available online: http://www.i-sis.org.uk/ fluidGenome.php (accessed on 2 August 2013).

16. Mattick, J.S.; Mehler, M.F. RNA editing, DNA recoding and the evolution of human cognition. Trends Neurosci. 2008, 31, 227-233.

17. Cheng, C.C.; Johnson, T.L.; Hoffmann, A. Epigenetic control: Slow and global, nimble and local. Gene. Dev. 2008, 22, 1110-1114.

18. Dietert, R.; Dietert, J. The completed self: An immunological view of the human-microbiome superorganism and risk of chronic diseases. Entropy 2012, 14, 2036-2065.

19. Kosoy, M. Deepening the conception of functional information in the description of zoonotic infectious diseases. Entropy 2013, 15, 1929-1962.

20. Oller, J.W., Jr. Biosemiotic Entropy: Disorder, Disease, and Mortality. Available online: http://www.mdpi.com/journal/entropy/special_issues/biosemiotic_entropy (accessed on 2 August 2013).

21. Tang, W.; Gei, Y.; Page, M. Biological significance of RNA editing in cells. Mol. Biotechnol. 2012, 52, 91-100. 
22. Agrawal, N.; Dasaradhi, P.V.N.; Mohmmed, A.; Malhotra, P.; Bhatnager, R.K.; Mukherhee, S.K. RNA interference: Biology, mechanism and applications. Microbiol. Mol. Biol. Rev. 2003, 67, 657-685.

23. Derr, L.K.; Strathern, J.N. A role for reverse transcripts in gene conversion. Nature 1993, 361, 170-173.

24. Ho, M.W. Subverting the genetic text. Sci. Soc. 2004, 24, 6-8.

25. Ho, M.W. Development and Evolution Revisited. In Handbook of Developmental Science, Behavior and Genetics; Hood, D., Halpern, C., Greenberg, G., Lerner, R., Eds.; Wiley: Chichester, UK, 2010; pp. 61-108.

26. Ho, M.W.; Cummins, J.; Saunders, P.T. GM food nightmare unfolding in the regulatory sham. Microb. Ecol. Health Dis. 2007, 19, 66-77.

27. Carman, J.A.; Vlieger, H.R.; Ver Steeg, L.J.; Sneller, V.E.; Robinson, G.W.; Clinch-Jones, C.A.; Hayes, J.I.; Edwards, J.W. A long-term toxicology study on pigs fed a combined genetically modified (GM) soy and GM mazie diet. J. Org. Sys. 2013, 8, 39-54.

28. Séralini, G.-E.; Clair, E.; Mesnage, R.; Gress, S.; Defarge, N.; Malatesta, M.; Hennequin, D.; de Vendômois, J.-S. Long term toxicity of a Roundup herbicide and a Roundup-tolerant genetically modified maize. Food Chem. Toxicol. 2012, 50, 4221-4231.

29. Saunders, P.T.; Ho, M.W. GM cancer warning can no longer be ignored. Sci. Soc. 2012, 56, $2-4$.

30. Saunders, P.T. Excess cancers and deaths with GM feed: The stats stand up. Sci. Soc. 2012, 56, 4-5.

31. Sirinathsinghji, E. GM soy linked to illnesses in farm pigs. Sci. Soc. 2012, 55, 8-9.

32. Séralini, G.-E.; Mesnage, R.; Clair, E.; Gress, S.; Spiroux de Vendôme, J.; Cellier, D. Genetically modified crops safety assessment: Present limits and possible improvements. Environ. Sci. Eur. 2011, 23, doi:10.1186/2190-4715-23-10.

33. Sirinathsinghji, E. GM feed toxic, meta-analysis reveals. Sci. Soc. 2011, 52, 30-32.

34. Ho, M.W. Emergency! Pathogen new to science found in Roundup Ready GM crops. Sci. Soc. 2011, 50, 10-11.

35. Ho, M.W. Scientist defends claim of new pathogen linked to GM crops. Sci. Soc. 2011, 50, 12-13.

36. Ermakova, I.V. Genetically modified soy leads to the decrease of weight and high mortality of rat pups of the first generation. Preliminary studies. EcosInform 2006, 1, 4-9.

37. Ho, M.W. GM soya-fed rats: Stunted, dead, or sterile. Sci. Soc. 2007, 33, 4-6.

38. Ho, M.W. More illnesses linked to Bt crops. Sci. Soc. 2006, 30, 8-10.

39. Ho, M.W. Mass deaths in sheep grazing on Bt cotton. Sci. Soc. 2006, 30, 12-13.

40. Prescott, V.E.; Campbell, P.M.; Moore, A.; Mattes, J.; Rothenberg, M.E.; Foster, P.S.; Higgins, T.J.V.; Hogan, S.P. Transgenic expression of bean a-amylase inhibitor in peas results in altered structure and immunogenicity. J. Agric. Food Chem. 2005, 53, 9023-9030.

41. Ho, M.W. Transgenic pea that makes mice ill. Sci. Soc. 2006, 29, 28-29.

42. Malatesta, M.; Caporaloni, C.; Rossi, L.; Battistelli, S.; Rocchi, M.B.L.; Tonucci, F.; Gazzanelli, G. Ultrastructural analysis of pancreatic acinar cells from mice fed on genetically modified soybean. J. Anat. 2002, 201, 409-415.

43. Malatesta, M.; Biggiogera, M.; Manuali, E.; Rochhi, M.B.L.; Baldelli, B.; Gazzanelli, G. Fine structural analyses of pancreatic acinar cell nuclei from mice fed on genetically modified soybean. Eur. J. Histochem. 2003, 47, 385-388. 
44. Malatesta, M.; Caporaloni, C.; Gavaudan, S.; Rocchi, M.B.L.; Serafini, S.; Tiberi, C.; Gazzanelli, G. Ultrastructural morphometrical and immunocytochemical analysis of hepatocyte nuclei from mice fed on genetically modified soybean. Cell Struct. Funct. 2002, 27, 175-180.

45. Malatesta, M.; Tiberi, C.; Baldelli, B.; Battistelli, S.; Manuali, E.; Biggiogera, M. Reversibility of hepatocyte nuclear modifications in mice fed on genetically modified soybean. Eur. J. Histochem. 2005, 49, 237-242.

46. Vecchio, L.; Cisterna, B.; Malatesta, M.; Martin, T.E.; Biggiogera, M. Ultrastructural analysis of testes from mice fed on genetically modified soybean. Eur. J. Histochem. 2004, 48, 449-454.

47. Ho, M.W. GM ban long overdue. Sci. Soc. 2006, 29, 26-27.

48. French experts very disturbed by health effects of Monsanto GM corn (translated from article in LeMonde). Available online: http://www.lobbywatch.org/archive2.asp?arcid=3308 (accessed on 15 October 2013).

49. Ho, M.W.; Burcher, S. Cows ate GM maize and died. Sci. Soc. 2004, 21, 4-6.

50. Sirinathsinghji, E. Syngenta charged for covering up livestock deaths from GM corn. Sci. Soc. 2012, 55, 4-5.

51. Pusztai, A.; Bardocz, S.; Ewen, S.W.B. Genetically Modified Foods: Potential Human Health Effects. In Food Safety: Contaminants and Toxins; D’Mello, J.P.F., Ed.; Scottish Agricultural College: Edinburgh, UK, 2003, pp. 347-371.

52. Fares, N.H.; El-Sayed, A.K. Fine structural changes in the ileum of mice fed on $\delta$-endotoxin-treated potatoes and transgenic potatoes. Nat. Toxins 1998, 6, 219-233.

53. Novotny, E. Animals avoid GM food, for good reasons. Sci. Soc. 2004, 21, 9-11.

54. Do seed companies control GM crop research? Available online: https://www.scientificamerican. com/article.cfm?id=do-seed-companies-control-gm-crop-research (accessed on 2 August 2013).

55. Ho, M.W.; Lim, L.C. The Case for a GM-Free Sustainable World; Independent Science Panel Report, Institute of Science in Society and Third World Network: London, UK, Penang, Malaysia, 2003.

56. Ho, M.W.; Lim, L.C. GM-Free, Exposing the Hazards of Biotechnology to Ensure the Integrity of Our Food Supply; Vitalhealth Publishing: Ridgefield, CT, USA, 2004.

57. Sirinathsinghji, E.; Ho, M.W. Double Jeopardy of Glyphosate and Glyphosate Tolerant Crops; In Ban GMOs Now; ISIS special report; Ho, M.W., Ed.; The Institute of Science in Society: London, UK, 2013.

58. Sirinathsinghji, E. Bt Crops Failing and Harmful to Health and the Environment. In Ban GMOs Now; ISIS special report; Ho, M.W., Ed.; The Institute of Science in Society: London, UK, 2013.

59. Selman, M.; Dankar, S.K.; Forbes, N.E.; Jia, J.-J.; Brown, E.G. Adaptive mutation in influenza A virus non-structural gene is linked to host switching and induces a novel protein by alternative splicing. Emerg. Microbe Infections 2012, 1, e53.

60. Ho, M.W. To mutate or not to mutate. Sci. Soc. 2004, 24, 9-10.

61. Ho, M.W. The Rainbow and the Worm, the Physics of Organisms, 3rd ed.; World Scientific: Singapore, Singapore, 2008.

62. Ho, M.W. Quantum computer? Is it alive? Available online: http://www.i-sis.org.uk/isisnews/ i-sisnews1 1-24.php\#quan (accessed on 2 August 2013). 
63. Ho, M.W. The real bioinformatics revolution-proteins and nucleic acids singing to one another? Sci. Soc. 2007, 33, 42-45.

64. Ho, M.W. Non-random directed mutations confirmed. Sci. Soc. 2013, 60, in press.

65. Wilson, A.; Latham, J.; Steinbrecher, R. Genome Scrambling Myth or Reality; Econexus Technical Report; Ecpmexis: Brighton, UK, 2004.

66. Bergelson, J.; Purrington, C.B.; Wichmann, G. Promiscuity in transgenic plants. Nature 1998, 395, doi:10.1038/25626.

67. Ho, M.W.; Traavik, T.; Olsvik, O.; Tappeser, B.; Howard, V.; von Weizsacker, C.; McGavin, G.C. Gene technology and gene ecology of infectious diseases. Microb. Ecol. Health Dis. 1998, 10, 33-39.

68. Ho, M.W. Horizontal gene transfer - the hidden hazards of genetic engineering. Available online: http://www.i-sis.org.uk/horizontal.php (accessed on 2 August 2013).

69. Ho, M.W. GM DNA does jump species. Sci. Soc. 2010, 47, 30-33.

70. Ho, M.W. Scientists discover new route for GM gene escape. Sci. Soc. 2011, 50, 14-15.

71. Syvanen, M., Kado, C.I., Eds. Horizontal Gene Transfer, 2nd ed.; Academic Press: Waltham, MA, USA, 2002.

72. Eisen, M. GMOs: Gene transfer is neither unnatural nor dangerous. Available online: http://www.science20.com/profile/michael_eisen (accessed on 2 August 2013).

73. Collonier, C.; Berthier, G.; Boyer, F.; Duplan, M.-N.; Fernandez, S.; Kebdani, N.; Kobilinsky, A.; Romanuk, M.; Bertheau, Y. Characterization of commercial GMO inserts: A source of useful material to study genome fluidity. Available online: http://www.crii-gen.org (accessed on 2 August 2013).

74. Ho, M.W. Transgenic lines proven unstable. Sci. Soc. 2003, 20, 35-36.

75. Ho, M.W. Unstable transgenic lines illegal. Sci. Soc. 2004, 21, 23.

76. Windels, P.; Taverniers, I.; Depicker, A.; van Bockstaele, E.; de Loose, M. Characterization of the Roundup Ready soybean insert. Eur. Food Res. Technol. 2001, 213, 107-112.

77. Hernández, M.; Pla, M.; Esteve, T.; Prat, S.; Puigdomènech, P.; Ferrando, A. A specific real-time quantitative PCR detection system for event MON810 in maize YieldGard based on the 3'-transgene integration sequence. Transgenic Res. 2003, 12, 170-189.

78. Singh, C.K.; Ojka, A.; Kamle, S.; Kachru, D.N. Assessment of cry1Ab transgene cassette in commercial Bt corn MON810: Gene, event, construct \& GMO specific concurrent characterization. Nat. Protoc. 2007, doi:10.1038/nprot.2007.440.

79. Rosati, A.; Bogani, P.; Santarlasci, A.; Buiatti, M. Characterisation of 4' transgene insertion site and derived mRNAs in MON810 YieldGard maize. Plant Mol. Biol. 2008, 67, 271-281.

80. Ho, M.W. MON 810 rearranged again. Sci. Soc. 2008, 38, 27.

81. Ho, M.W. Transgenic lines unstable hence illegal and ineligible for protection. Sci. Soc. 2008, $38,28-29$.

82. Yin, Z.; Plader, W.; Malepszy, S. Transgene inheritance in plants. J. Appl. Genet. 2004, 45, 127-144.

83. Ho, M.W.; Cummins, J. Gene therapy risks exposed. Sci. Soc. 2003, 19, 48-50.

84. Somers, D.A.; Makarevitch, I. Transgene integration in plants: Poking or patching holes in promiscuous genomes? Curr.Opin. Biotech. 2004, 15, 126-131.

85. Wu, B.; Sun, Y.H.; Wang, Y.W.; Wang, Y.P.; Zhu, Z.Y. Characterization of transgene integration pattern in F4hGH-transgenic common carp (Cyprinus carpio L.). Cell Res. 2005, 15, 447-454. 
86. Reim, S.; Hanke, V. Investigation on stability of transgenes and their expression in transgenic apple plants (Malus x domestica Borkh). Acta. Hort. 2004, 663, 419-424.

87. Flachowsky, J.; Riedel, M.; Reim, S.; Hanke, M.-V. Evaluation of the uniformity and stability of T-DNA integration and gene expression in transgenic apple plants. Electron. J. Biotech. 2008, 11, doi:10.2225/vol11-issue1-fulltext-10.

88. Roman, E.; Soares, A.; Proite, K.; Neiva, S.; Grossi, M.; Faria, J.C.; Rech, E.L.; Aragão, F.J.L. Transgene elimination in genetically modified dry bean and soybean lines. Genet. Mol. Res. 2005, 4, 177-184.

89. GMO and BIOHAZ Units. Consolidated presentation of the joint Scientific Opinions of the GMO and BIOHAZ panels on "Use of Antibiotic Resistance Genes as Marker Genes in Genetically Modified Plants" and the Scientific Opinion of the GMO Panel on "Consequences of the Opinion on the Use of Antibiotic Resistance Genes as Marker Genes in Genetically Modified Plants on Previous EFSA Assessments of Individual GM Plants" (Statement of EFSA. EFSA-Q-2009-00589 and EFSA-Q-2009-00593). EFSA J. 2009, 1108, 1-8.

90. De Vries, J.; Herzfeld, T.; Wackernagel, W. Transfer of plastid DNA from tobacco to the soil bacterium Acinetobacter sp. By natural transformation. Mol. Microbiol. 2004, 53, 323-334.

91. De Vries, J.; Meier, P.; Wackernagel, W. Microbial horizontal gene transfer and the DNA release from transgenic crop plants. Plant Soil 2004, 266, 91-104.

92. Simpson, D.J.; Fry, J.C.; Rogers, H.J.; Day, M.J. Transformation of Acinetobacyer baylyi in non-sterile soil using recombinant plant nuclear DNA. Environ. Biosaf. Res. 2007, 6, 101-112.

93. Rizzi, A.; Pontiroli, A.; Brusetti, L.; Borin, S.; Solini, C.; Abruzzese, A.; Sacchi, G.A.; Vogel, T.M.; Simonet, P.; Bazzicalupo, M.; et al. Strategy for in situ detection of natural transformation-based horizontal gene transfer events. Appl. Environ. Microbiol. 2008, 74, 1250-1254.

94. Pontiroli, A.; Rizzi, A.; Simonet, P.; Daffonchio, D.; Vogel, T.M.; Monier, J.M. Visual evidence of horizontal gene transfer between plants and bacteria in the phytosphere of transplastomic tobacco. Appl. Environ. Microbiol. 2009, 75, 3314-3322.

95. Chen, J.; Jin, M.; Qiu, Z.G.; Guo, C.; Chen, Z.L.; Shen, Z.Q.; Wang, X.W.; Li, J.W. A survey of drug resistance bla genes originating from synthetic plasmid vectors in six Chinese rivers. Environ. Sci. Tech. 2012, 46, 13448-13454.

96. Sirinathsinghji, E. GM antibiotic resistance in China's rivers. Sci. Soc. 2013, 57, 6-7.

97. Chowdhury, E.H.; Mikami, O.; Nakajima, Y.; Hino, A.; Kuribara, H.; Suga, K.; Hanazumi, M.; Yomemochi, C. Detection of genetically modified maize DNA fragments in the gastrointestinal contents of pigs fed StarLink CBH351. Vet. Hum. Toxicol. 2003, 45, 95-96.

98. Reuter, T.; Aulrich, K. Investigations on genetically modified maize (Bt-maize) in pig nutrition: Fate of feed-ingested foreign DNA in pig bodies. Eur. Food Res. Technol. 2003, 216, 185-192.

99. Duggan, P.S.; Chambers, P.A.; Heritage, J.; Forbes, J.M. Fate of genetically modified maize DNA in the oral cavity and rumen of sheep. Brit. J. Nutr. 2003, 89, 159-166.

100. Phipps, R.H.; Deaville, E.R.; Maddison, B.C. Detection of transgenic and endogenous plant DNA in rumen fluid, duodenal digesta, milk, blood and faeces of lactating dairy cows. J. Dairy Sci. 2003, 86, 4070-4078.

101. Ho, M.W. DNA in GM food \& feed. Sci. Soc. 2004, 23, 34-36. 
102. Netherwood, T.; Martin-Orue, S.M.; O-Donnell, A.G.; Gockling, S.; Graham, J.; Mathers, J.C.; Gilbert, J.H. Assessing the survival of transgenic plant DNA in the human gastrointestinal tract. Nat. Biotechnol. 2004, 22, 204-209.

103. Netherwood, T.; Bowden, R.; Harrison, P.; O’Donnell, A.G.; Parker, D.S.; Gilbert, H.J. Gene transfer in the gastrointestinal tract. Appl. Environ. Microb. 1999, 65, 5139-5141.

104. Kelly, B.G.; Vespermann, A.; Bolton, D.J. Gene transfer events and their occurrence in selected environments. Food Chem. Toxicol. 2009, 47, 978-983.

105. McCuddin, Z.; Carlson, S.A.; Rasmussen, M.A.; Franklin, S.K. Klebsiella to Salmonella gene transfer within rumen protozoa: Implications for antibiotic resistance and rumen defaunation. Vet. Microb. 2005, 114, 275-284.

106. Mercer, D.K.; Scott, K.P.; Bruce-Johnson, W.A.; Glover, L.A.; Flint, H.J. Fate of free DNA and transformation of the oral bacterium Streptococcus gordonii DL by plasmid DNA in human saliva. Appl. Environ. Microb. 1999, 65, 6-10.

107. Ho, M.W.; Ryan, A.; Cummins, J.; Traavik, T. Slipping Through the Regulatory Net: Naked and Free Nucleic Acids; TWN: Penang, Malaysia, 2001.

108. Podevin, N.; du Jardin, P. Possible consequences of the overlap between the CaMV 35S promoter regions in plant transformation vectors used and the viral gene VI in transgenic plants. GM Crop. Food 2012, 3, 1-5.

109. Ho, M.W. Hazardous virus gene discovered in GM crops after 20 years. Sci. Soc. 2013, 57, $2-3$.

110. Latham, J.; Wilson, A. Potentially dangerous virus gene hidden in commercial GM crops. Sci. Soc. 2013, 57, 4-5.

111. Ho, M.W.; Ryan, A.; Cummins, J. Cauliflower mosaic viral promoter-a recipe for disaster? Microb. Ecol. Health Dis. 1999, 11, 194-197.

112. Ho, M.W.; Ryan, A.; Cummins, J. Hazards of transgenic plants with the cauliflower mosaic viral promoter. Microb. Ecol. Health Dis. 2000, 12, 6-11.

113. Ho, M.W.; Ryan, A.; Cummins, J. CaMV35S promoter fragmentation hotspot confirmed and it is active in animals. Microb. Ecol. Health Dis. 2000, 12, doi:10.1080/089106000750051864.

114. Ballas, N.; Broido, S.; Soreq, H.; Loyter, A. Efficient functioning of plant promoters and poly(A) sites in Xenopus oocytes. Nucl. Acids Res. 1989, 17, 7891-7903.

115. Burke, C.; Yu, X.B.; Marchitelli, L.; Davis, E.A.; Ackerman, S. Transcription factor IIA of wheat and human function similarly with plant and animal viral promoters. Nucl. Acids Res. 1990, 18, 3611-3620.

116. Cui, X.; Fan, B.; Scholz, J.; Chan, Z. Roles of Arabidopsis cyclin-dependent kinase C complexes in cauliflower mosaic virus infection, plant growth and development. Plant Cell 2007, 19, 1388-1402.

117. Ho, M.W.; Cummins, J. New evidence links CaMV 35S promoter to HIV transcription. Microb. Ecol. Health Dis. 2009, 21, 172-174.

118. Hazards of GMOS: Agrobacterium mediated transformation. Available online: http://www.bristol.ac.uk/news/2010/7279.html (accessed on 2 August 2013).

119. Knight, C.J.; Bailey, A.M.; Foster, G.D. Investigating Agrobacterium-mediated transformation of Verticillium albo-atrum on plant surfaces. PLoS One 2010, 5, e13684. 
120. McNicol, M.J.; Lyon, G.D.; Chen, M.Y.; Barrett, C.; Cobb, E. The Possibility of Agrobacterium as a Vehicle for Gene Escape; R\&D and Surveillance Report, Contract No. RG 0202; Scottish Crop Research Institute: Scotland, UK, 1996.

121. Barrett, C.; Cobb, E.; MacNiCol, R.; Lyon, G. A risk assessment study of plant genetic transformation using Agrobacterium and implication for analysis of transgenic plants. Plant Cell Tiss. Org. Cult. 1997, 19, 135-144.

122. Mogilner, N.; Zutra, D.; Gafny, R.; Bar-Joseph, M. the persistence of engineered Agrobacterium tumefaciens in agroinfected plants. Mol. Plant-Microb. Interact. 1993, 6, 673-675.

123. Soltani, J.; van Heusden, P.H.; Hooykaas, P.J.J. Agrobacterium-Mediated Transformation of Non-Plant Organisms. In Agrobacterium: From Biology to Biotechnology; Tzfira, T., Citovsky, V., Eds.; Springer: New York, NY, USA, 2008; pp. 649-674.

124. Ho, M.W. Horizontal gene transfer from GMOs does happen. Sci. Soc. 2008, 38, 22-24.

125. Ferguson, G.; Heinemann, J. Recent History of Trans-Kingdom Conjugation. In Horizontal Gene Transfer, 2nd ed.; Syvanen, M., Kado, C.I., Eds.; Academic Press: San Diego, CA, USA, 2002; pp. 3-17.

126. Ho, M.W. Horizontal gene transfer. Heredity 2003, 90, 6-7.

127. Kado, C. Horiontal Transmission of Genes by Agrobacterium Species. In Horizontal Gene Transfer, 2nd ed.; Syvanen, M., Kado, C.I., Eds.; Academic Press: San Diego, CA, USA, 2002, pp. 45-50.

128. Sengelov, G.; Kristensen, K.J.; Sorensen, A.H.; Kroer, N.; Sorensen, S.J. Effect of genomic location on horizontal transfer of a recombinant gene cassette between Pseudomonas strains in the rhizosphere and spermosphere of barley seedlings. Curr. Microb. 2001, 42, 160-167.

129. Kunik, T.; Tzfira, T.; Kapulnik, Y.; Gafni, Y.; Dingwall, C.; Citovsky, V. Genetic transformation of HeLa cells by Agrobacterium. Proc. Natl. Acad. Sci. USA 2001, 98, 1871-1876.

130. Cummins, J. Common plant vector injects genes into human cells. Available online: http://www.i-sis.org.uk/Agrobacterium.php (accessed on 2 August 2013).

131. CDC to launch study on unexplained illness. Available online: http://www.cdc.gov/od/oc/ media/transcripts/2008/t080116.htm\#id=45169 (accessed on 2 August 2013).

132. Unexplained Dermopathy (aka "Morgellons"). Available online http://www.cdc.gov/ unexplaineddermopathy/general_info.html (accessed on 2 August 2013).

133. Ho, M.W.; Cummins, J. Agrobacterium \& Morgellons disease, a GM connection? Sci. Soc. 2008, $38,33-36$.

134. Savely, V.R.; Leitao, M.M.; Stricker, R.B. The mystery of Morgellons disease, infection or delusion? Am. J. Clin. Dermatol. 2006, 7, 1-5.

135. Stricker, R.B.; Savely, V.R.; Saltsman, A.; Citovsky, V. Contribution of Agrobacterium to Morgellons disease. J. Invest. Med. 2007, 55 (Suppl.), S123.

136. Pearson, M.L.; Selby, J.V.; Katz, K.A; Cantrell, V.; Braden, C.R.; Parise, M.E.; Paddock, C.D.; Lewin-Smith, M.R.; Kalasinsky, V.F.; Goldstein, F.C.; et al. Clinical, epidemiologic, histopathologic and molecular features of an unexplained dermopathy. PLoS One 2012, 7, e29908.

137. Heinemann, J.A.; Agapito-Tenfen, S.Z.; Carman, J.A. A comparative evaluation of the regulation of GM crops or products containing dsRNA and suggested improvements to risk assessment. Environ. Int. 2013, 55, 43-55. 
138. Fire, A.; Xu, S.; Montgomery, M.K.; Kostas, S.A.; Diver, S.E.; Mello, C.C. Potent and specific genetic interference by double-stranded RNA in Caenorhabditis elegans. Nature 1998, 391, 806-811.

139. Cogoni, C.; Macino, G. Post-transcriptional gene silencing across kingdoms. Curr. Opin. Genet. Dev. 2000, 10, 638-643.

140. Hawkins, P.G.; Sharon, S.S.; Adams, C.; Anest, V.; Morris, K.V. Promoter targeted small RNAs induce long-term transcriptional gene silencing in human cells. Nucl. Acids Res. 2009, 37, doi:10.1093/nar/gkp127.

141. Alder, M.N.; Dames, S.; Gaudet, J.; Mango, S.E. Gene silencing in Caernorhabditis elegans by transitive NA interference. RNA 2003, 9, 25-32.

142. Ho, M.W. Epigenetic inheritance, what genes remember. Sci. Soc. 2009, 41, 4-5.

143. Ho, M.W. New GM nightmares with RNA. Sci. Soc. 2013, 58, 6-7.

144. Zhang, L.; Hou, D.; Chen, X.; Li, D.; Zhu, L.; Zhang, Y.; Li, J.; Bian, Z.; Liang, X.; Cai, X.; et al. Exogenous plant MiR168a specifically targets mammalian LDIRAP1: Evidence of cross-kingdom regulation by microRNA. Cell Res. 2012, 22, 107-126.

145. Ho, M.W. How food affects genes. Sci. Soc. 2012, 53, 12-13.

146. Zhang, Y.; Wiggins, E.; Lawrence, C.; Petrick, J.; Ivashuta, S.; Heck, G. Analysis of plant-derived miRNAs in animal small RNA datasets. BCM Genomics 2012, 13, doi:10.1186/1471-2164-13-381.

147. Thermo Scientific Tech Support. Off-target effects: disturbing the silence of RNA interference (RNAi). Available online: http://www.thermoscientificbio.com/uploadedFiles/Resources/ off-target-tech-review.pdf (accessed on 2 August 2013).

148. Helwak, A.; Kudla, G.; Dudnakova, T.; Tollervey, D. Mapping the human miRNA Interactome by CLASH reveals frequent noncanonical binding. Cell 2013, 153, 654-665.

149. Ho, M.W. RNA interference "complex and flexible" \& beyond control. Sci. Soc. 2013, 59, in press.

150. Grimm, D.; Streetz. K.L.; Jopling, C.L.; Storm, T.A.; Pandey, K.; Davis, C.R.; Marion, P.; Salazar, F.; Kay, M.A. Fatality in mice due to oversaturation of cellular microRNA/shorthairpin RNA pathways. Nature 2006, 441, 537-541.

151. Ho, M.W. Gene therapy nightmare for mice could human be next? Sci. Soc. 2006, 31, 25.

152. Couzin, J. RNAi shows cracks in its armor. Science 2004, 306, 1124-1125.

153. Ho, M.W. Controversy over gene therapy breakthrough. Sci. Soc. 2005, 26, 38.

154. Heinemann, J.A. Update on "Evaluation of risks from creation of novel RNA molecules in genetically engineered wheat plants and recommendations for risk assessment". Rocky Mountain Laboratories, Hamilton, MT, USA. Personal communication, 21 March 2013.

155. Ho, M.W. Human genome map spells death of genetic determinism. ISIS News 2001, 7/8, 1-2. Available online: http://www.i-sis.org.uk/isisnews/i-sisnews7-1.php (accessed on 2 August 2013).

156. Ho, M.W. Ten years of the human genome. Sci. Soc. 2010, 48, 22-25.

157. Zuk, O.; Hechter, E.; Sunyaev, S.R.; Lander, E.R. The mystery of missing heritability: Genetic interactions create phantom heritability. Available online: http://www.pnas.org/cgi/coi/10.1073/ pnas.1119685109 (accessed on 2 August 2013).

158. Ho, M.W. Mystery of missing heritability solved? Sci. Soc. 2012, 53, 26-31.

159. Ho, M.W. No genes for intelligence. Sci. Soc. 2012, 53, 28-31.

160. Ho, M.W. No genes for intelligence in the fluid genome. Adv. Child Dev. Behav. 2013, 45, 67-92.

161. Ribozyme. Available online: http://en.wikipedia.org/wiki/Ribozyme (accessed on 2 August 2013). 
162. Wiedenheft, B.; Sternberg, S.H.; Doudna, J.A. RNA-guided genetic silencing systems in bacteria and archaea. Nature 2012, 482, 331-338.

163. Ho, M.W. Intercommunication via circulating nucleic acids. Sci. Soc. 2009, 42, 46-48.

164. Liu, Y. A new perspective on Darwin's Pangenesis. Biol. Rev. 2008, 83, 141-149.

165. Ho, M.W. Darwin's pangenesis, the hidden history of genetics \& the dangers of GMOs. Sci. Soc. 2009, 42, 42-45.

166. Spadafora, C. Sperm-mediated "reverse" gene transfer: A role of reverse transcriptase in the generation of new genetic information. Hum. Reprod. 2008, 23, 735-740.

167. Ho, M.W. Epigenetic inheritance through sperm cells, the Lamarckian dimension in evolution. Sci. Soc. 2009, 42, 40-42.

168. Rasoulzadegan, M.; Grandjean, V.; Gounon, P.;.Vicent, S.; Gillot, I.; Cuzin, F. RNA-mediated non-Mendelian inheritance of an epigenetic change in the mouse. Nature 2006, 441, 469-474.

169. Corrado, C.; Raimondo, S.; Chiesi, A.; Ciccia, F.; de Leo, G.; Alessandro, R. Exosomes as intercellular signaling organelles involved in health and disease: basic science and clinical applications. Int. J. Mol. Sci. 2013, 14, 5338-5366.

170. Sahoo, S.; Klychkod, E.; Thorne, T.; Misener, S.; Schultz, K.M.; Milay, M.; Ito, A.; Liu, T.; Kamide, C.; Agrawal, H.; et al. Exosomes from human CD34+ stem cells mediate the proangiogenic paracrine activity. Circ. Res. 2011, 109, 724-728.

171. Bergsmedh, A.; Szeles, A.; Henriksson, M.; Bratt, A.; Foldman, M.J.; Spetz, A.-L.; Holmgren, L. Horizontal transfer of oncogenes by uptake of apoptotic bodies. Proc. Natl. Acad. Sci. USA 2001, 98, 6407-6411.

172. Beling, M.; Wittrup, A. Nanotubes, exosomes, and nucleic acid-binding peptides provide novel mechanisms of intercellular communication in eukaryotic cells: implications in health and disease. J. Cell Biol. 2008, 183, 1187-1191.

173. Van der Vaart, M.; Pretorius, P.J. Circulating DNA, its origins and fluctuation. Ann. N. Y. Acad. Sci. 2008, 1137, 18-26.

174. Gahan, P.B.; Ander, P.; Stroun, M. Metabolic DNA as the origin of spontaneously released DNA? Ann. N. Y. Acad. Sci. 2008, 1137, 7-17.

175. Gahan, P.B.; Stroun, M. The Biology of CNAPS. In Extracellular Nucleic Acids; Rykova, E.Y., Kikuchi, Y., Eds.; Springer: Berlin, Germany, 2010.

176. Beck, J.; Urnovitz, H.B.; Riggert, J.; Cierici, M.; Schütz, E. Profile of the circulating DNA in apparently healthy individuals. Clin. Chem. 2009, 55, 730-738.

177. Yakubov, L.A.; Petrova, N.A.; Popova, N.A.; Semenov, D.V.; Nikolin, V.P.; Os'kina, I.N. The role of extracellular DNA in the stability and variability of cell genomes. Dokl. Biochem. Biophys. 2002, 382, 31-34.

178. Yakubov, L.A.; Rogachev, V.A.; Likhacheva, A.C.; Bogachev, S.S.; Seeleva, T.E.; Shilov, A.G.; Baiborodin, S.I.; Petroa, N.; Mechelina, L.V.; Shurdov, M.A.; et al. Natural human gene correction by small extracellular genomic DNA fragments. Cell Cycle 2007, 6, 2293-2301.

(C) 2013 by the author; licensee MDPI, Basel, Switzerland. This article is an open access article distributed under the terms and conditions of the Creative Commons Attribution license (http://creativecommons.org/licenses/by/3.0/). 